Supporting Information for:

Steric control between neutral metal-only Lewis pairs and metal-stabilized gallenium and gallinium cations

Holger Braunschweig, * Rian D. Dewhurst, Christoph Schneider

Institut für Anorganische Chemie, Julius-Maximilians-Universität Würzburg, Am Hubland, 97074

Würzburg 
NMR spectra of prepared compounds

\section{Complex 1b}

${ }^{1} H$ NMR spectrum

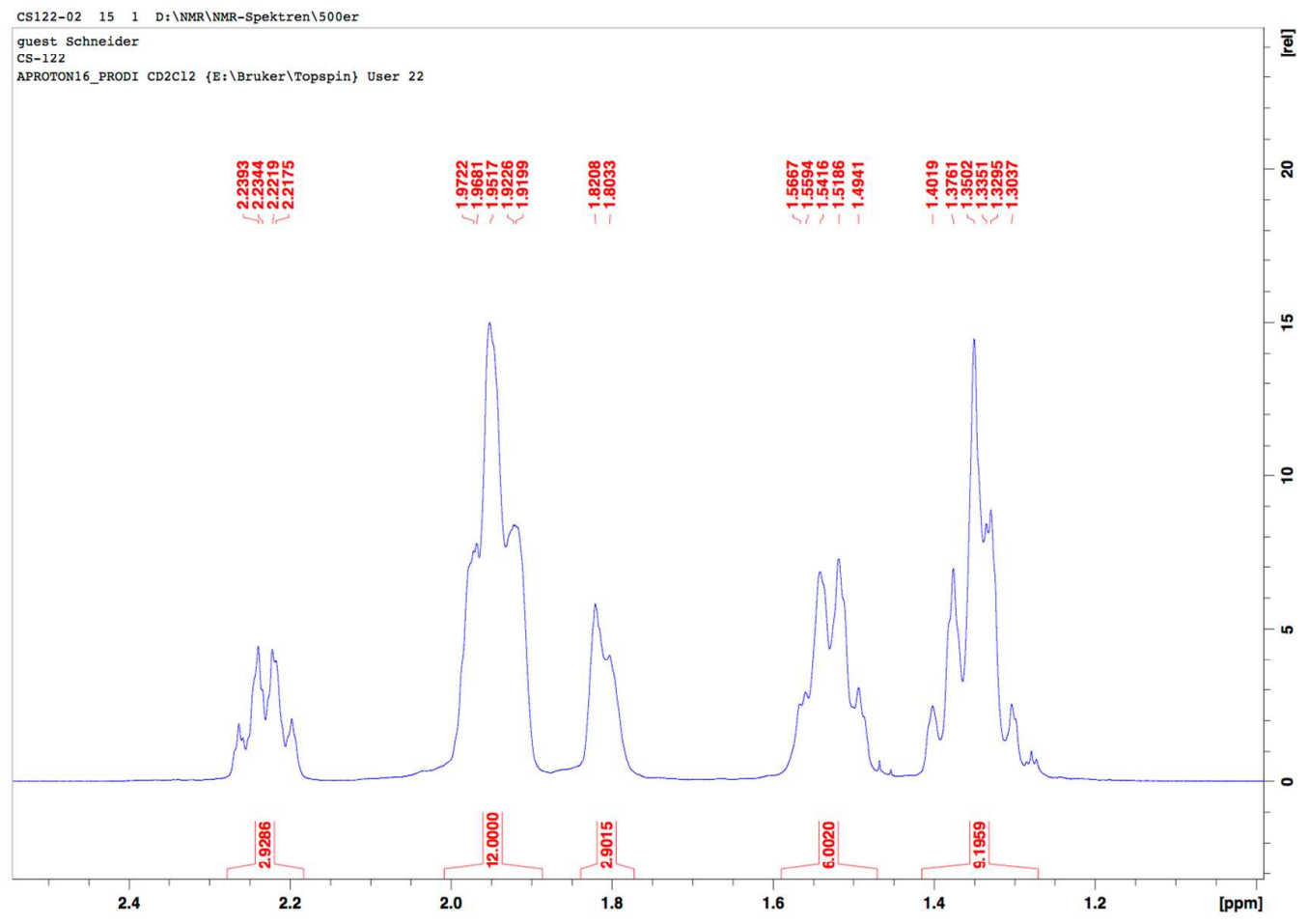


${ }^{13} C\left\{{ }^{1} H\right\}$ NMR spectrum

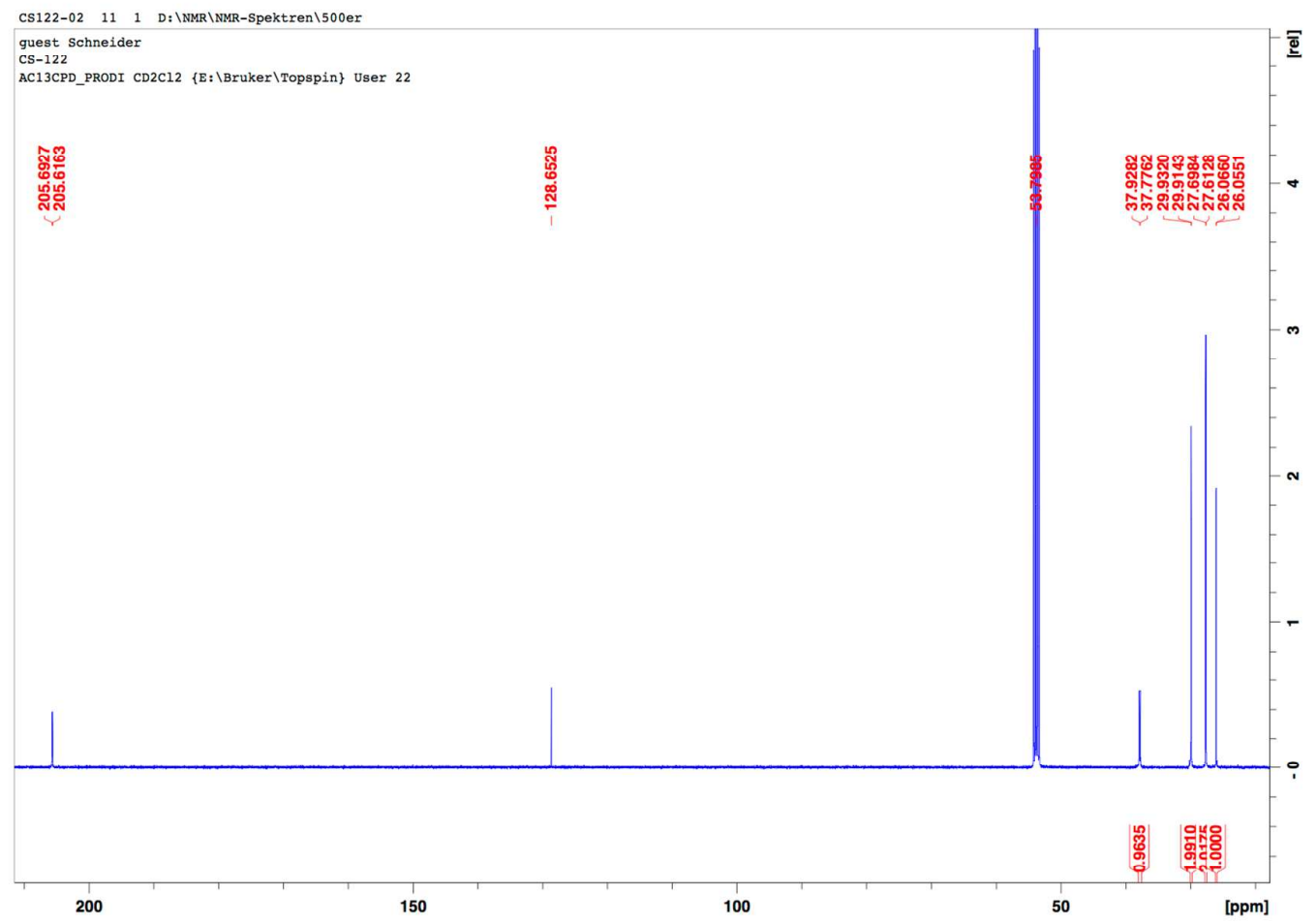

The signal at 53.84 represents the $\mathrm{CD}_{2} \mathrm{Cl}_{2}$ signal. 
${ }^{31} P\left\{{ }^{l} H\right\} N M R$ spectrum

CS122-02 $13 \quad 1 \quad D:$ : INMR \NMR-Spektren $\backslash 500$ er

guest Schneider
CS-122
AP31CPD CD2C12 \{B: \Bruker \Topspin $\}$ User 22

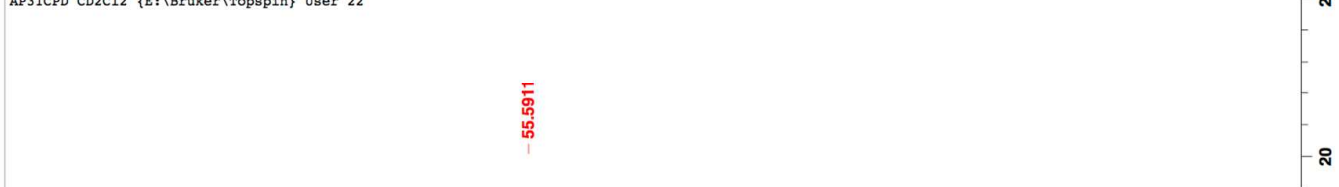

สิ

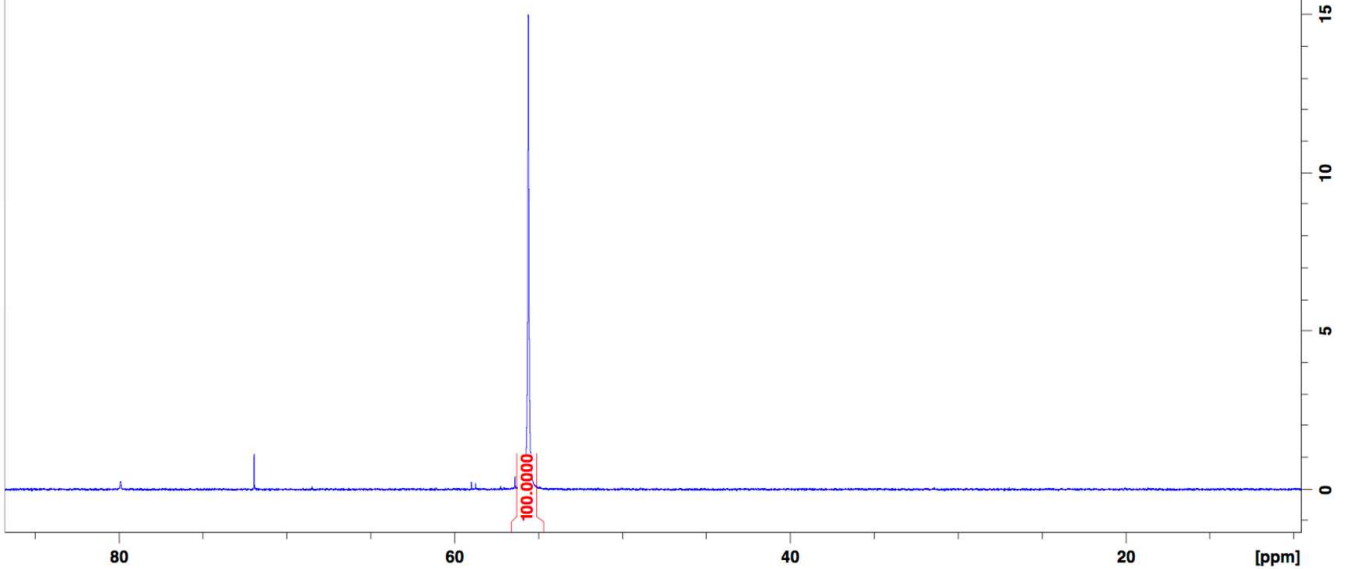

[ppm] 


\section{Complex 2b}

${ }^{I} H$ NMR spectrum

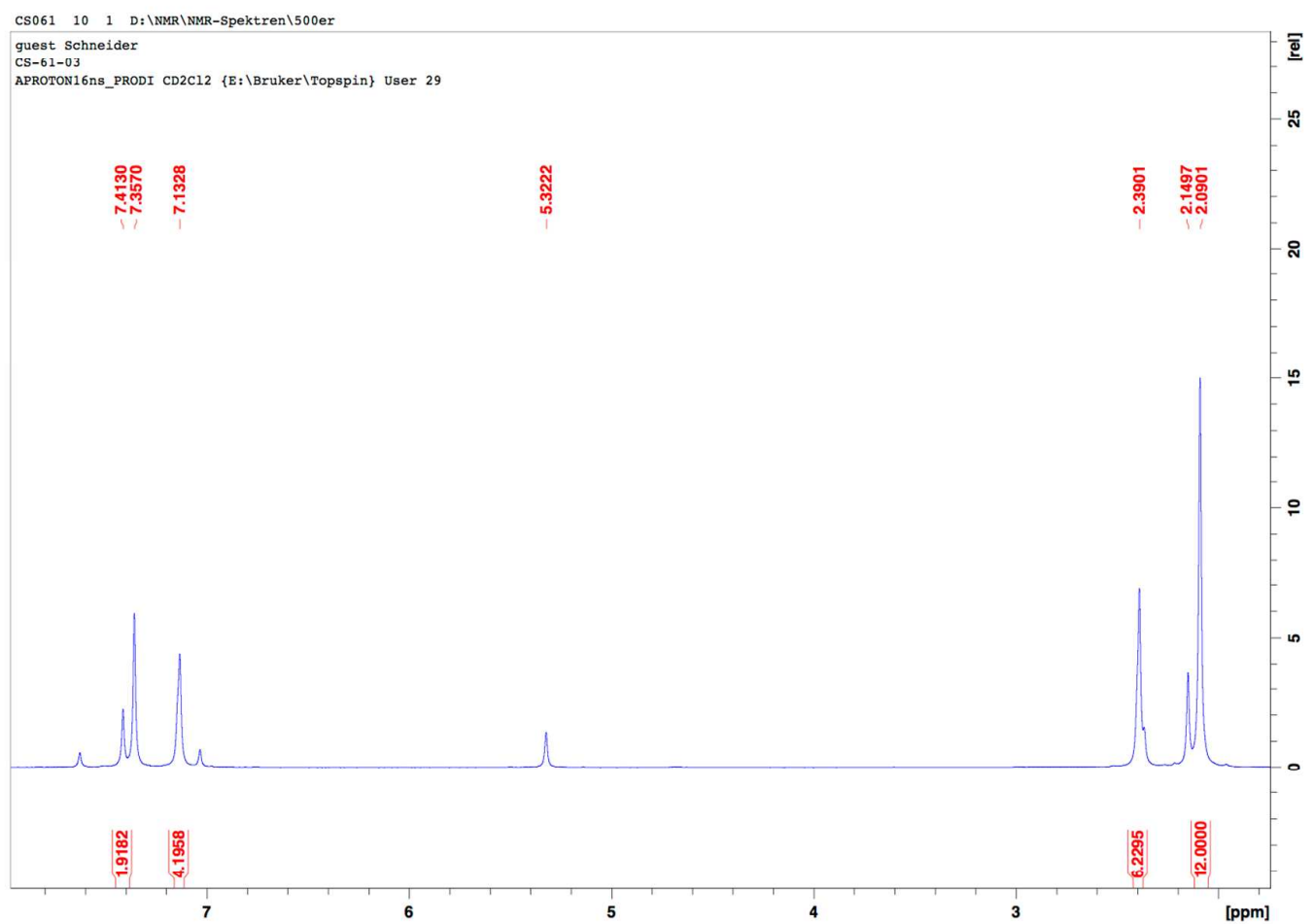

The signal at 5.32 represents the $\mathrm{CD}_{2} \mathrm{Cl}_{2}$ signal. Due to slow decomposition of $\mathbf{2 b}$ in solution the ${ }^{1} \mathrm{H}$ NMR spectrum also shows small signals of decomposition compounds. 
${ }^{13} C\left\{{ }^{1} H\right\}$ NMR spectrum

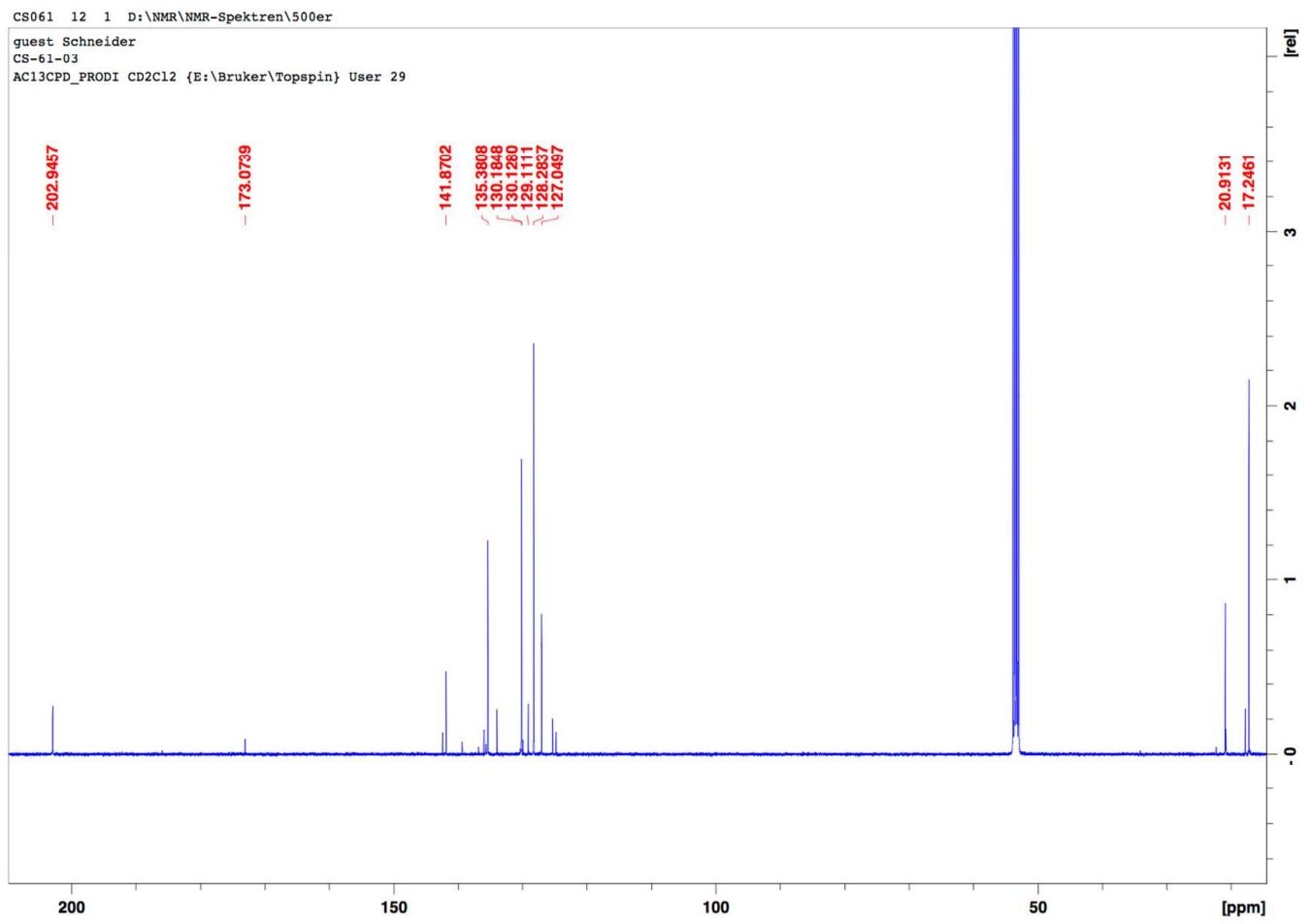

The signal at 53.84 represents the $\mathrm{CD}_{2} \mathrm{Cl}_{2}$ signal. Due to slow decomposition of $\mathbf{2 b}$ in solution the ${ }^{13} \mathrm{C}$ NMR spectrum also shows small signals of decomposition compounds. 


\section{Complex 3a}

${ }^{1} H$ NMR spectrum

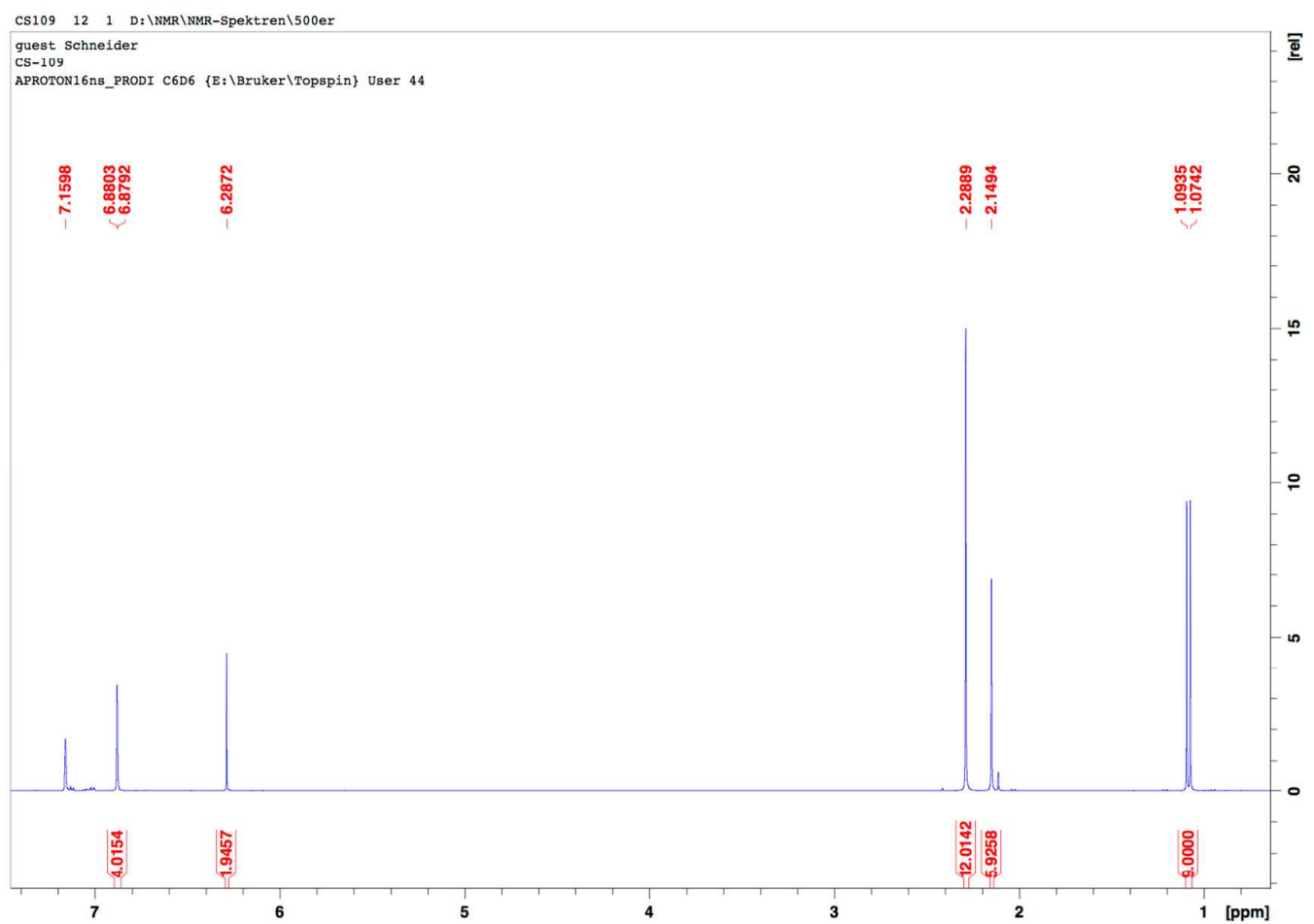

The signal at 7.16 represents the $\mathrm{C}_{6} \mathrm{D}_{6}$ signal. 
${ }^{13} C\left\{{ }^{1} H\right\}$ NMR spectrum

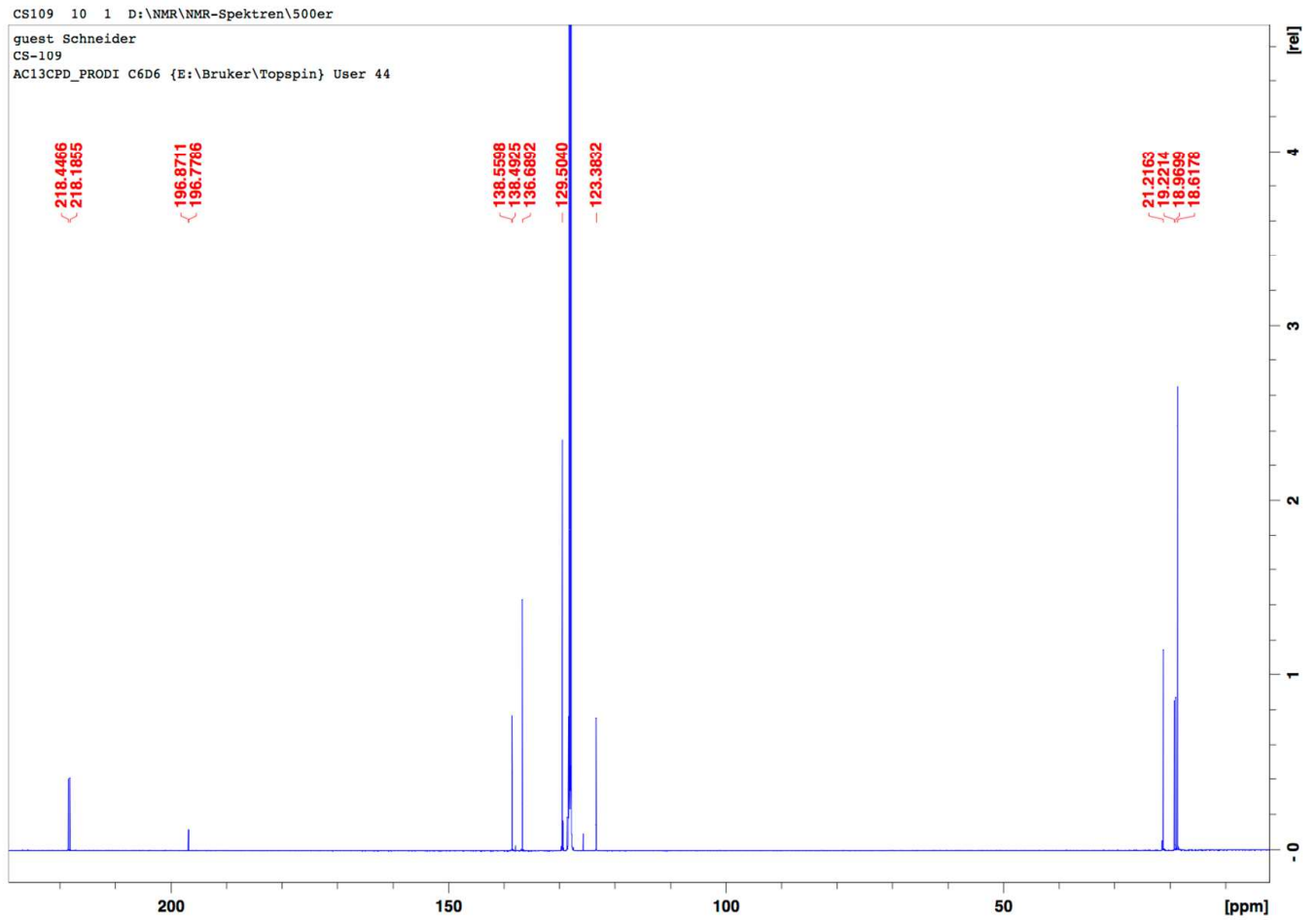

The signal at 128.06 represents the $\mathrm{C}_{6} \mathrm{D}_{6}$ signal. 
${ }^{31} P\left\{{ }^{l} H\right\}$ NMR spectrum

Cs109 $13 \quad 1 \quad D: \backslash$ NMR $\backslash$ MMR-Spektren $\backslash 500$ er guest Schneider
CS-109

AP31CPD C6D6 \{E:\Bruker|Topspin\} User 44
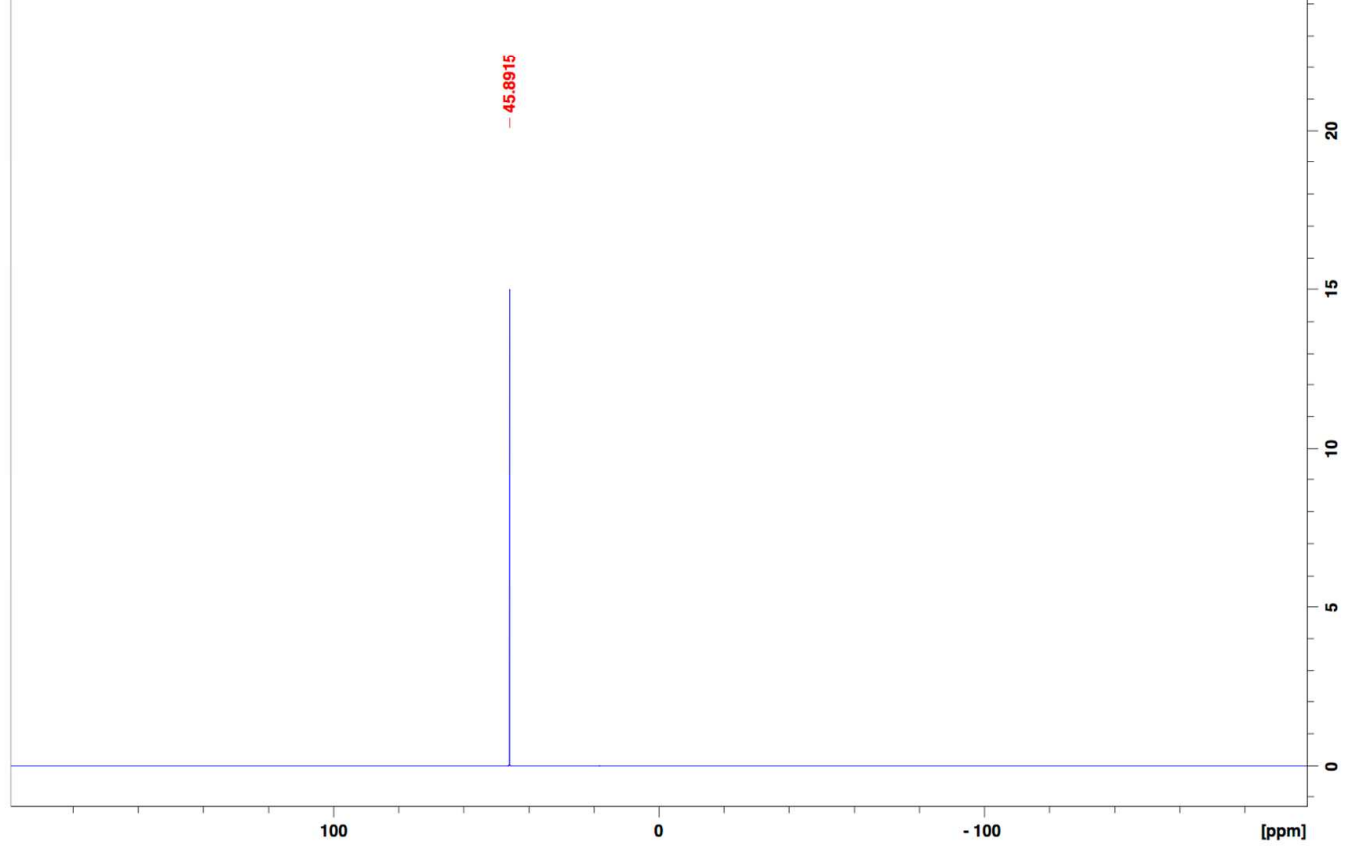


\section{Mixture of isomers 3b/c}

${ }^{1}$ H NMR spectrum

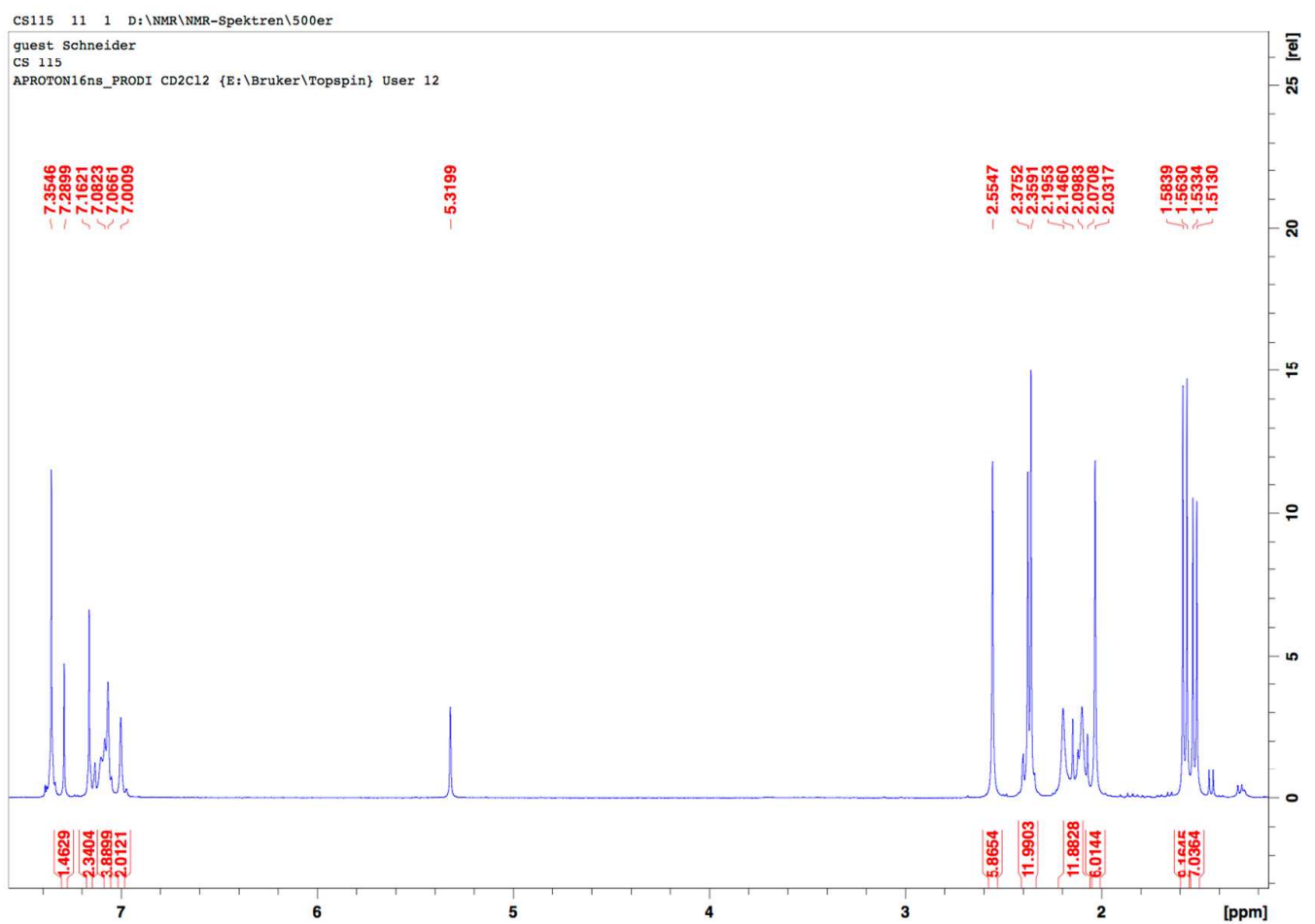

The signal at 5.32 represents the $\mathrm{CD}_{2} \mathrm{Cl}_{2}$ signal and the signal at 7.35 can be assigned to benzene from the preparation. Due to slow decomposition of $\mathbf{3 b} / \mathbf{c}$ in solution the ${ }^{1} \mathrm{H}$ NMR spectrum also shows small signals of decomposition compounds. 
${ }^{13} C\left\{{ }^{1} H\right\}$ NMR spectrum

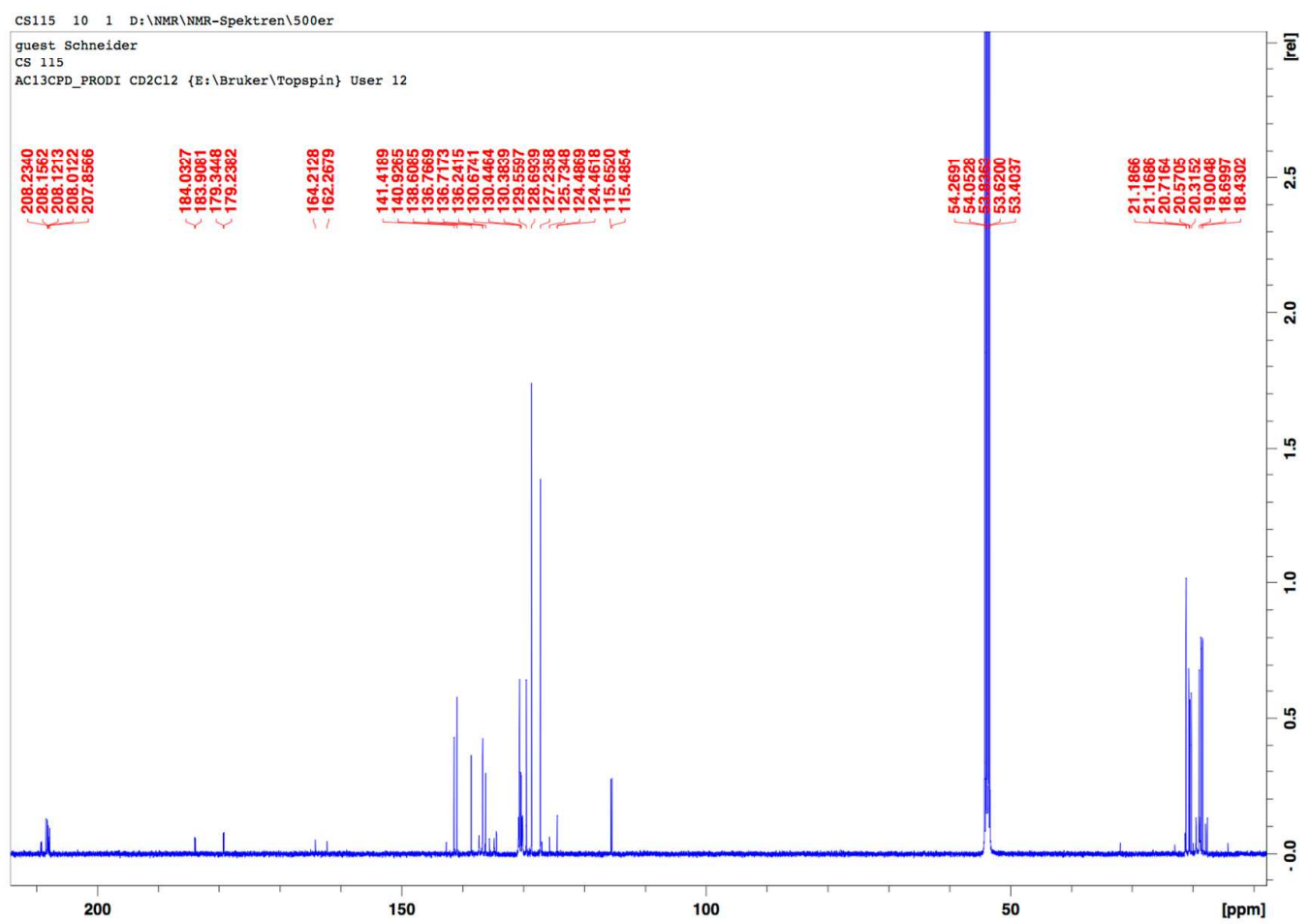

The signal at 53.84 represents the $\mathrm{CD}_{2} \mathrm{Cl}_{2}$ signal and the signal at 128.69 can be assigned to benzene from the preparation. Due to slow decomposition of $\mathbf{3 b} / \mathbf{c}$ in solution the ${ }^{1} \mathrm{H}$ NMR spectrum also shows small signals of decomposition compounds. 
${ }^{31} P\left\{{ }^{1} H\right\}$ NMR spectrum

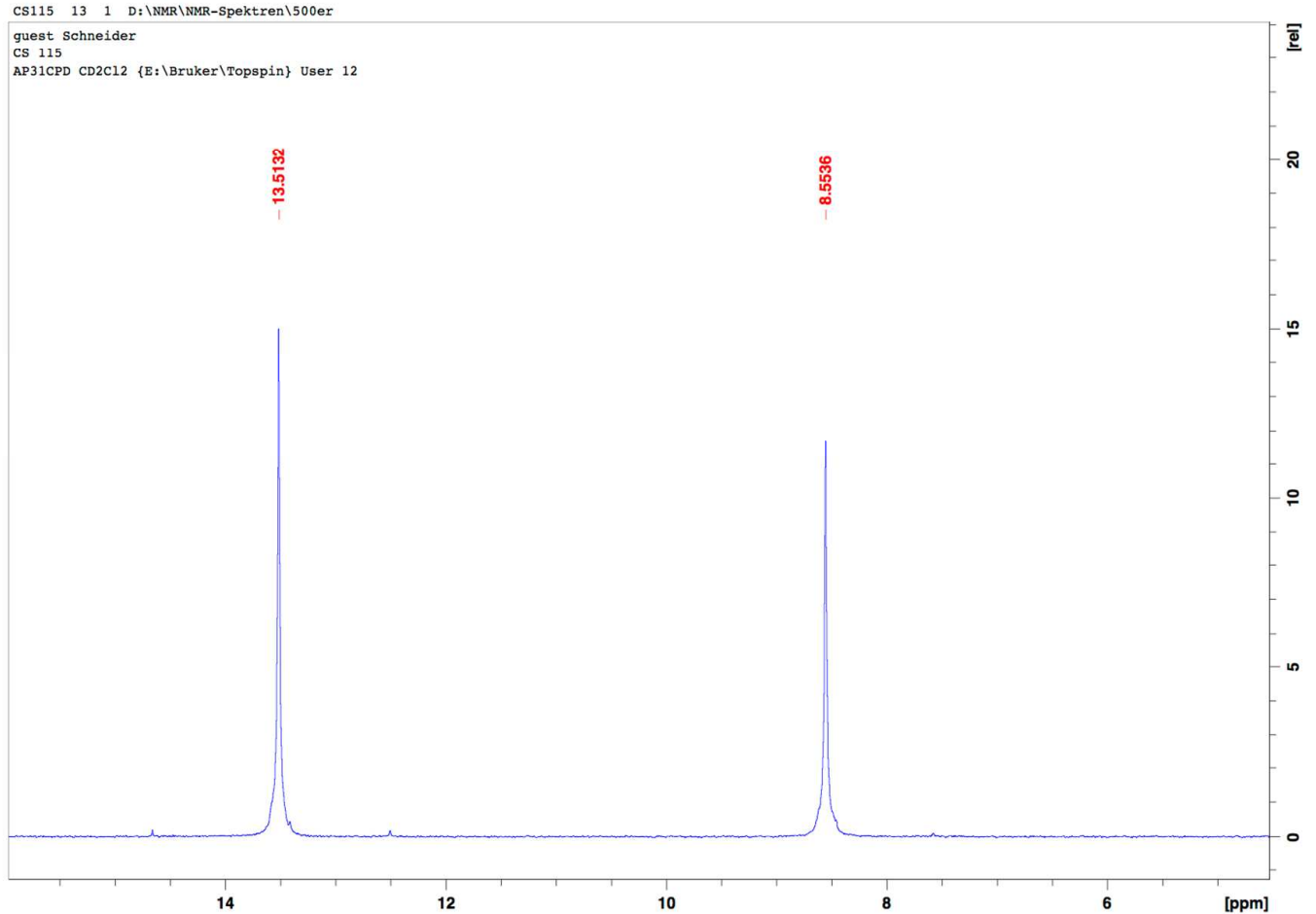




\section{Complex 4a}

${ }^{1} H$ NMR spectrum

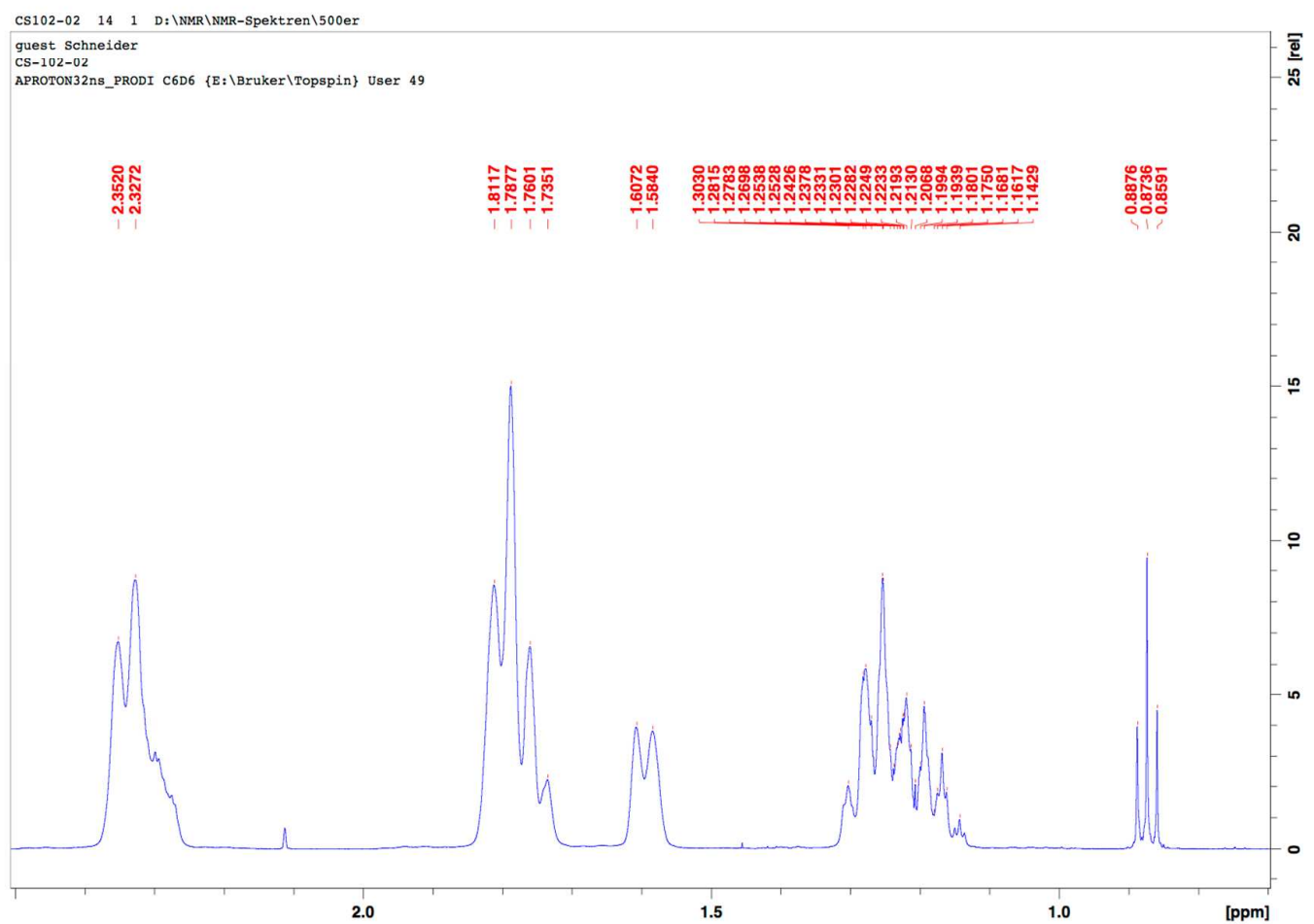

The signal at 0.88 can be assigned to pentane from the preparation. 
${ }^{13} C\left\{{ }^{1} H\right\} N M R$ spectra
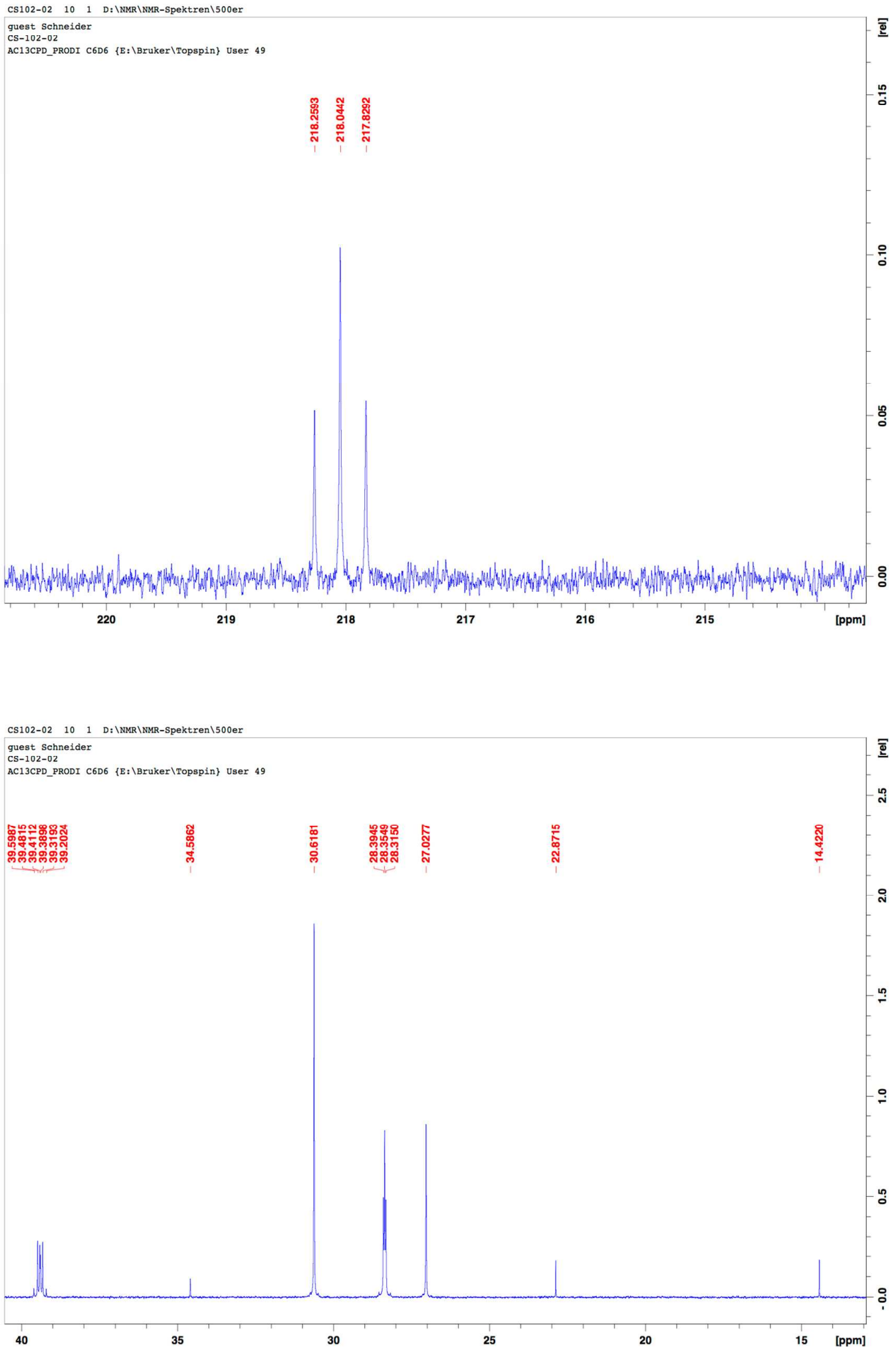

The signals at $14.42,22.87$ and 34.58 can be assigned to pentane from the preparation. 
${ }^{31} P\left\{{ }^{l} H\right\} N M R$ spectrum

CS102-02 $13 \quad 1 \quad$ D: \NMR \NMR-Spektren 1500 er

guest Schneider
CS-102-02

AP31CPD C6D6 \{E:\Bruker\Topspin\} User 49

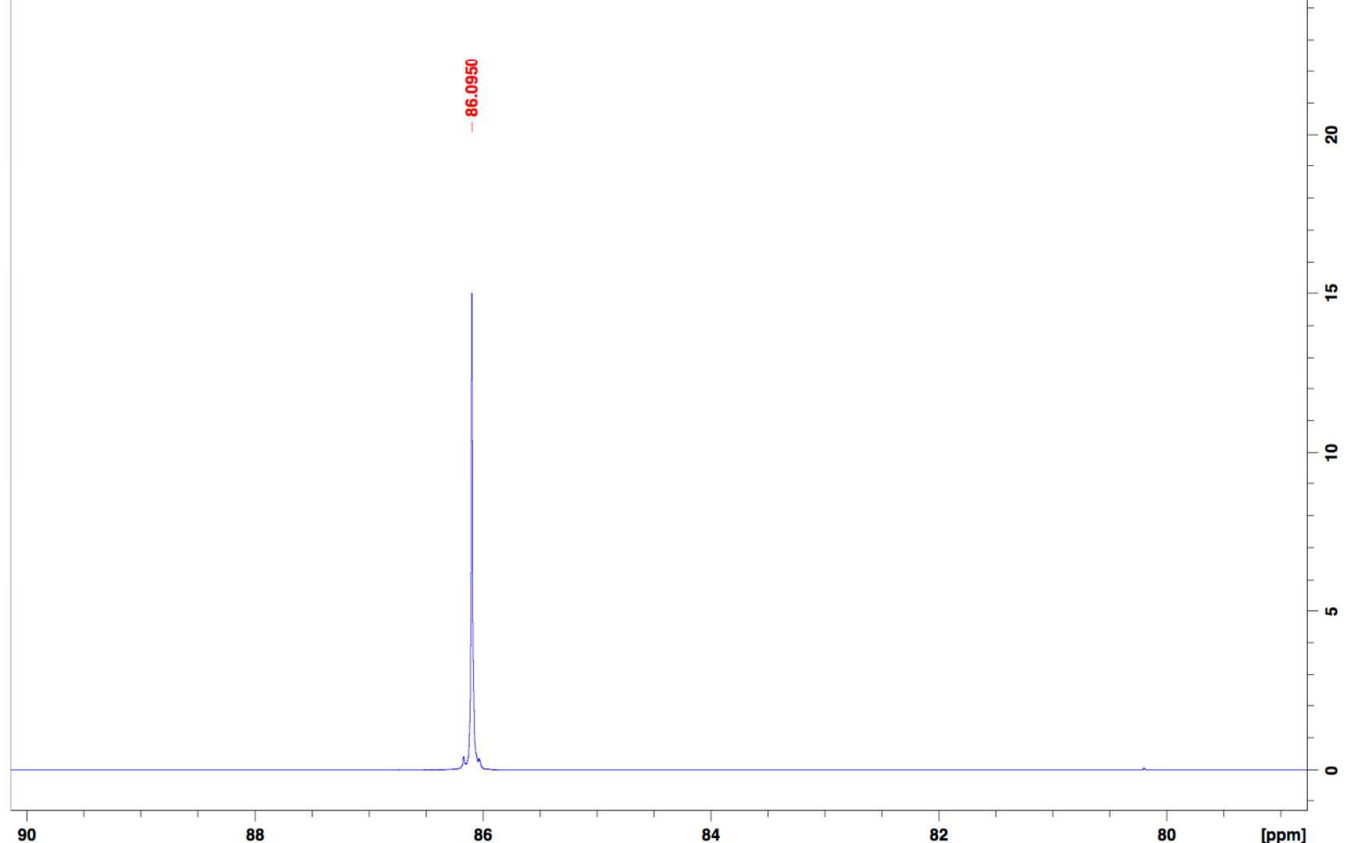




\section{Complex 4b}

${ }^{1} H$ NMR spectrum

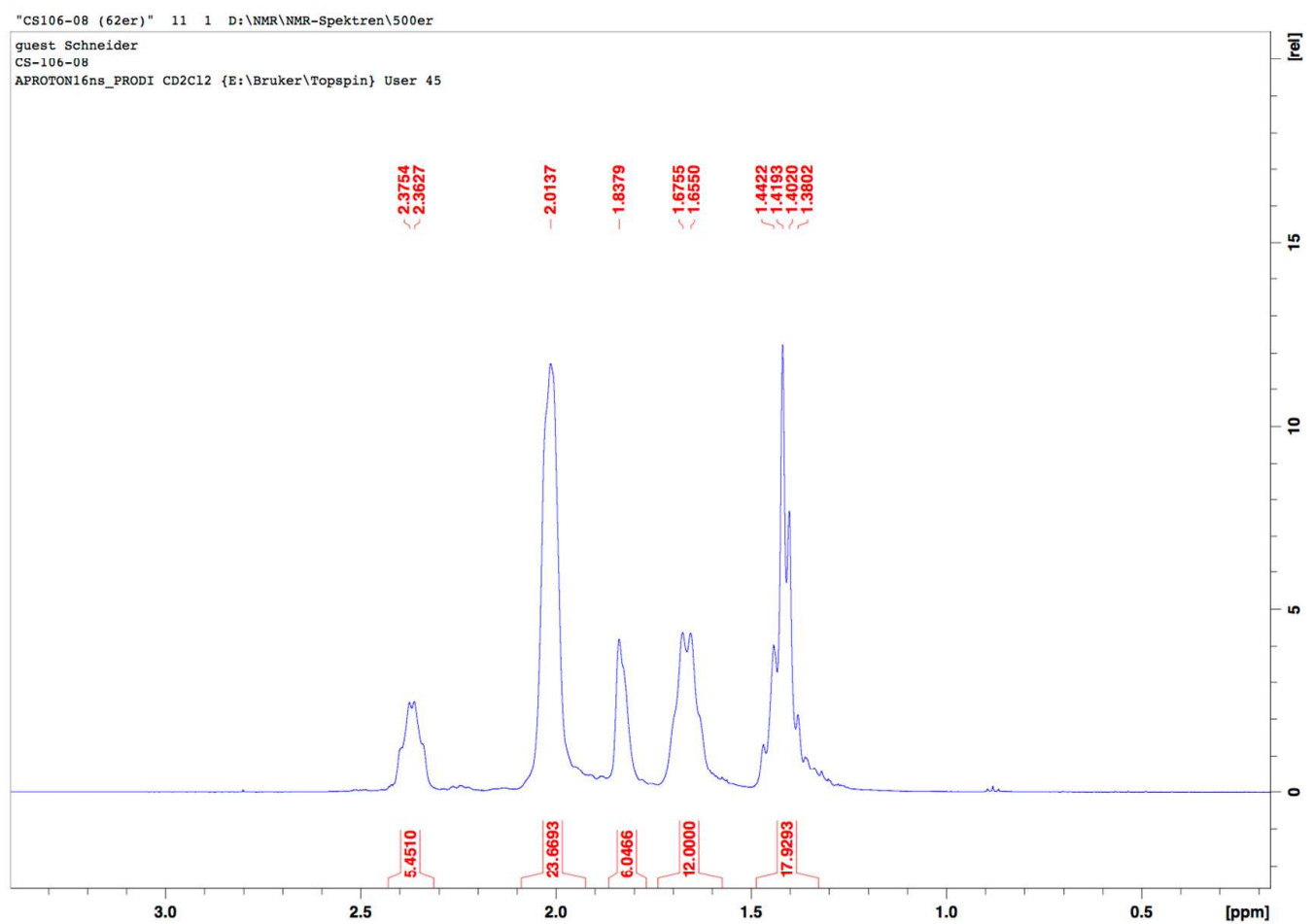


${ }^{13} C\left\{{ }^{1} H\right\}$ NMR spectrum

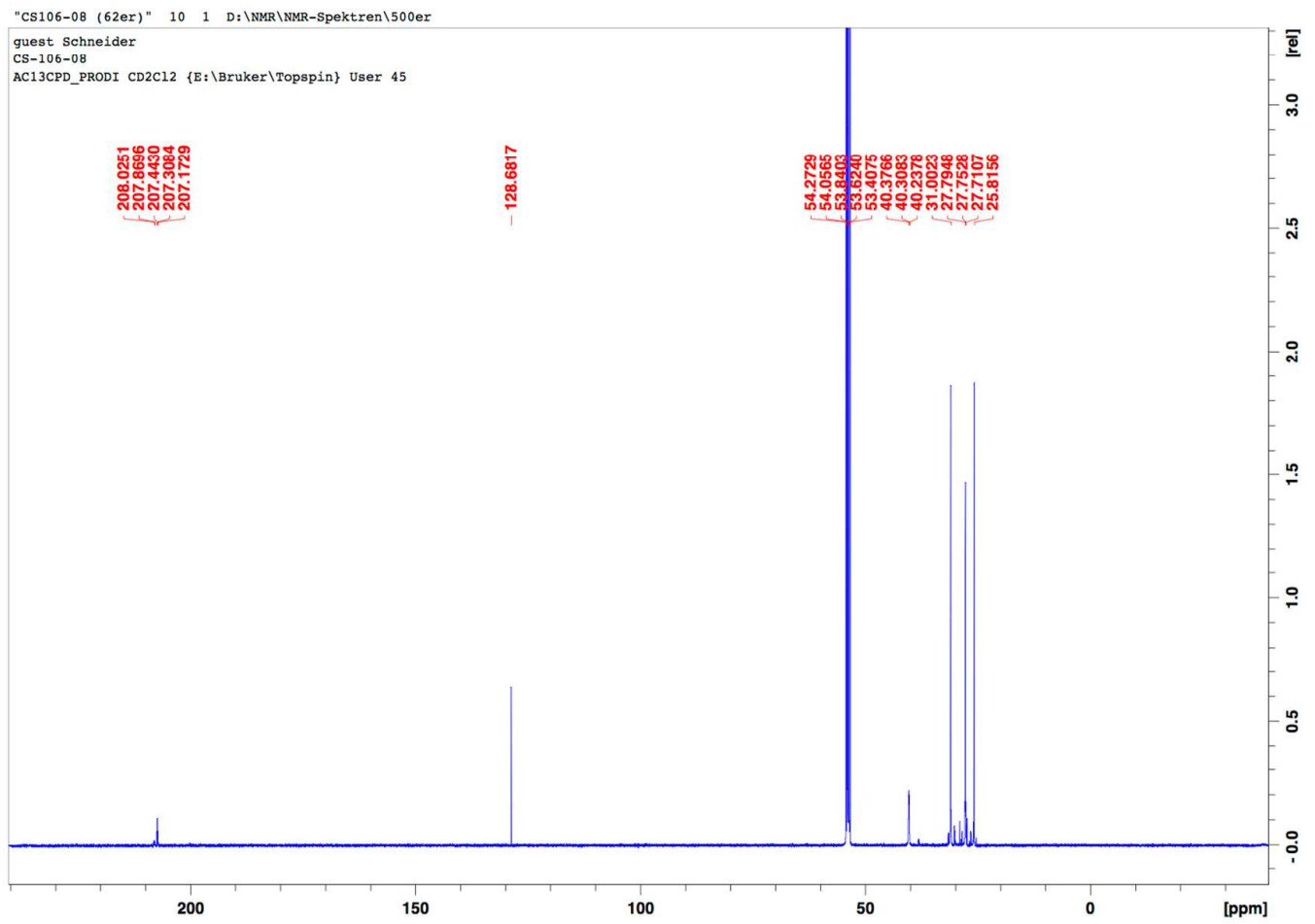

The signal at 53.84 represents the $\mathrm{CD}_{2} \mathrm{Cl}_{2}$ signal and the signal at 128.68 can be assigned to benzene from the preparation. Due to slow decomposition of $\mathbf{4 b}$ in solution the ${ }^{13} \mathrm{C}$ NMR spectrum also shows small signals of decomposition compounds. 
${ }^{31} P\left\{{ }^{1} H\right\} N M R$ spectrum

"CS106-08 (62er)" $13 \quad 1 \quad$ D: \NMR \NMR-Spektren $\backslash 500 e r$

guest Schneider

AP31CPD CD2C12 \{B: \Bruker\Topspin\} User 45

$\underline{\underline{\underline{\mathbf{s}}}}$

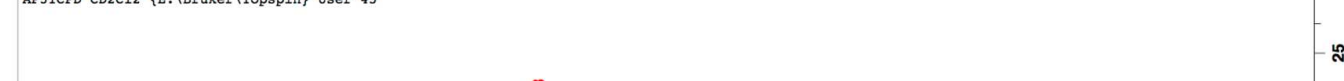

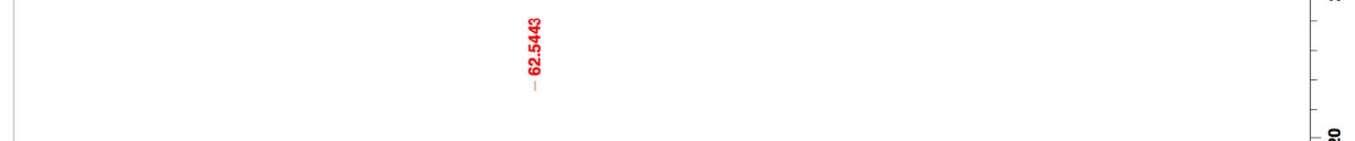

-
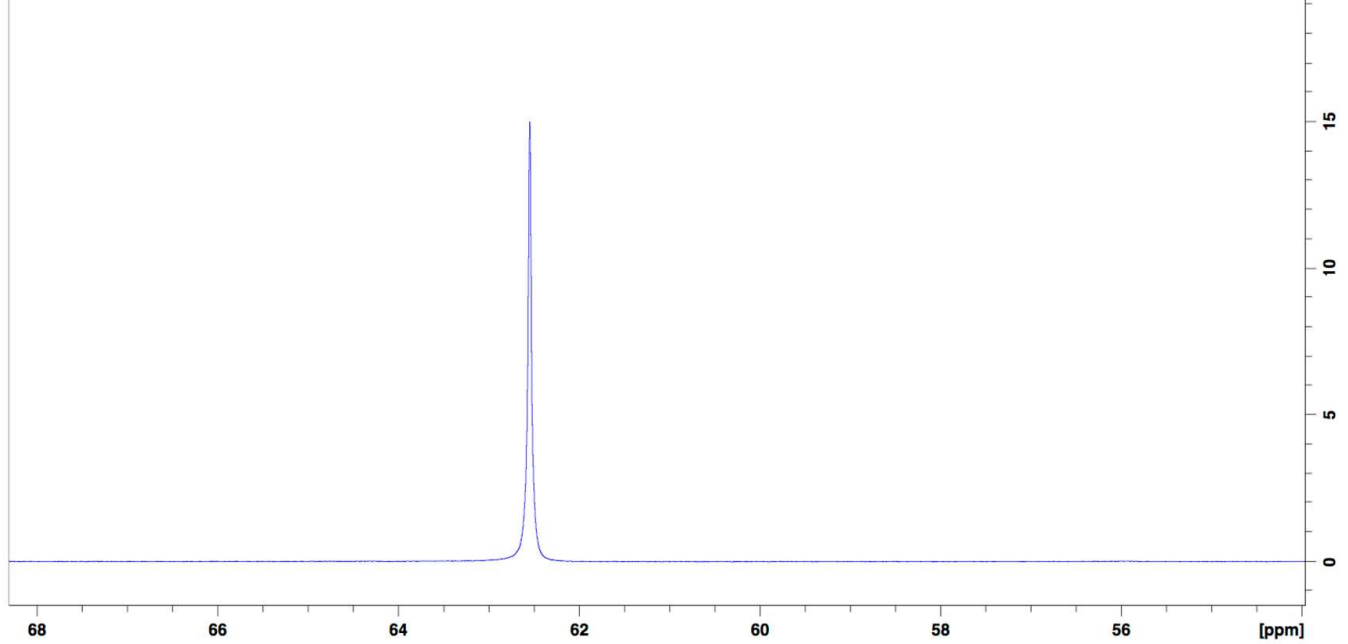


\section{Complex 5b}

${ }^{1}$ H NMR spectrum

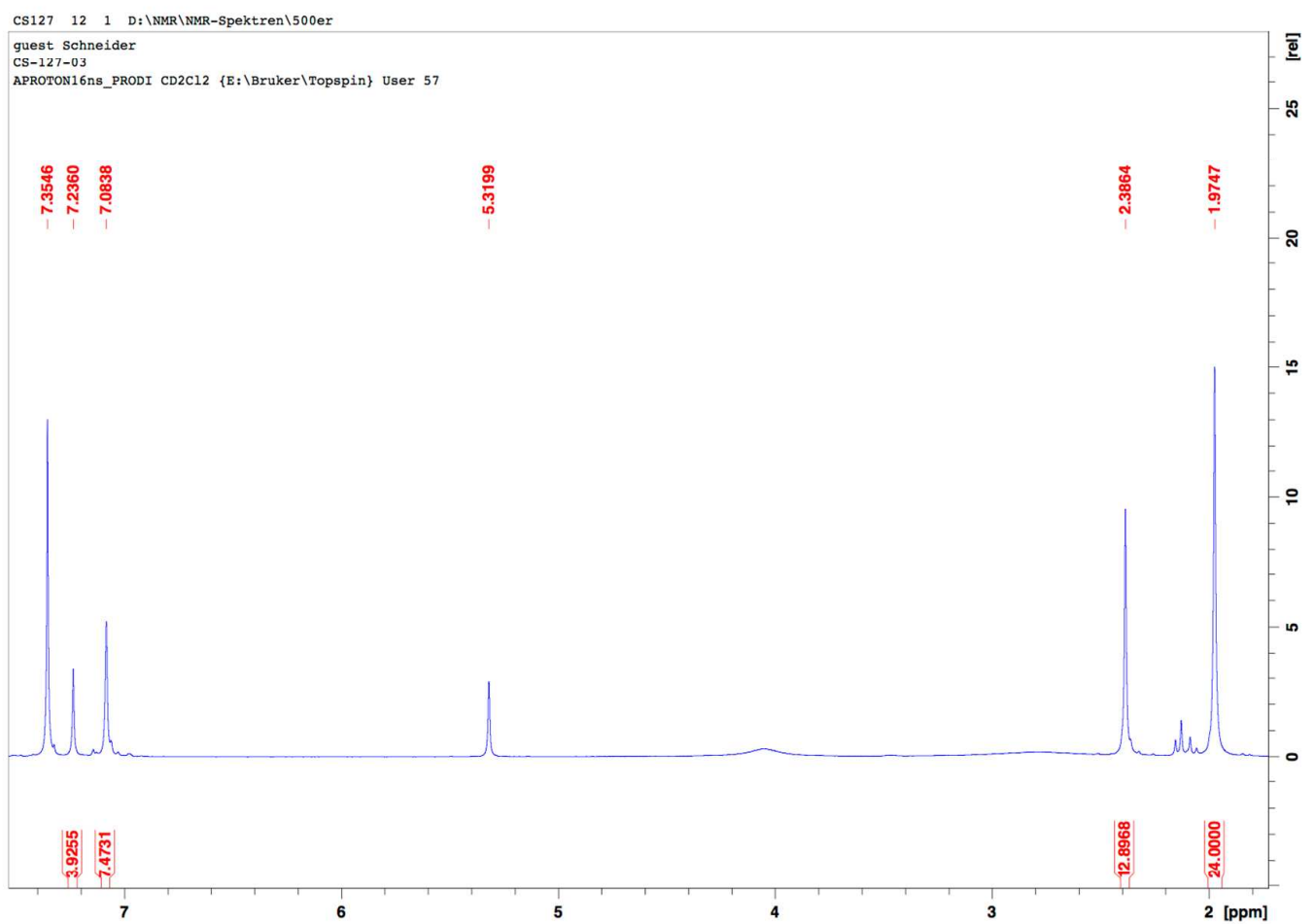

The signal at 5.32 represents the $\mathrm{CD}_{2} \mathrm{Cl}_{2}$ signal and the signal at 7.35 can be assigned to benzene from the preparation. Due to slow decomposition of $\mathbf{5 b}$ in solution the ${ }^{1} \mathrm{H}$ NMR spectrum also shows small signals of decomposition compounds. 
${ }^{13} C\left\{{ }^{1} H\right\}$ NMR spectrum

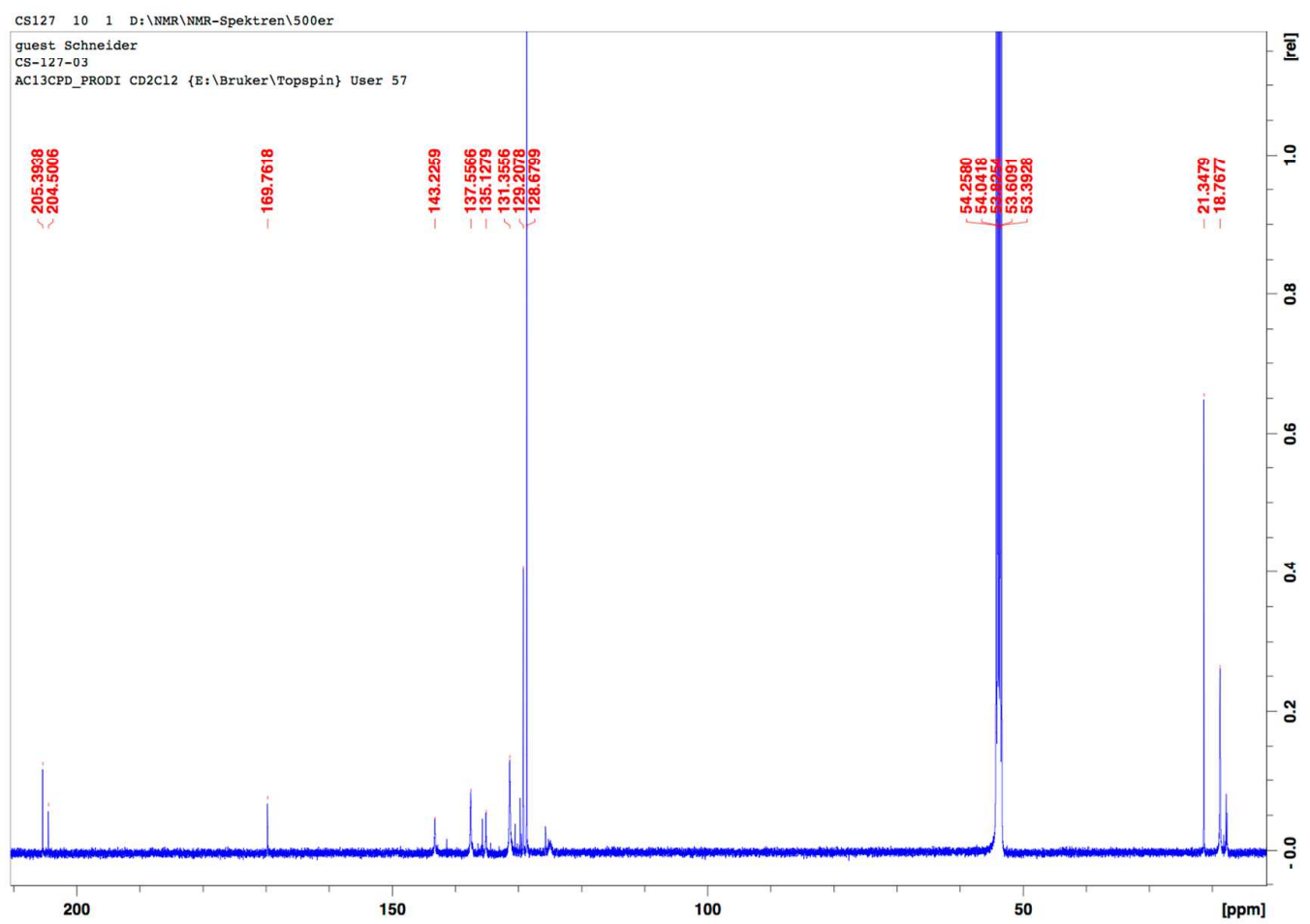

The signal at 53.84 represents the $\mathrm{CD}_{2} \mathrm{Cl}_{2}$ signal and the signal at 128.68 can be assigned to benzene from the preparation. Due to slow decomposition of $\mathbf{5 b}$ in solution the ${ }^{13} \mathrm{C}$ NMR spectrum also shows small signals of decomposition compounds. 


\section{Complex 6a}

${ }^{I} H$ NMR spectrum

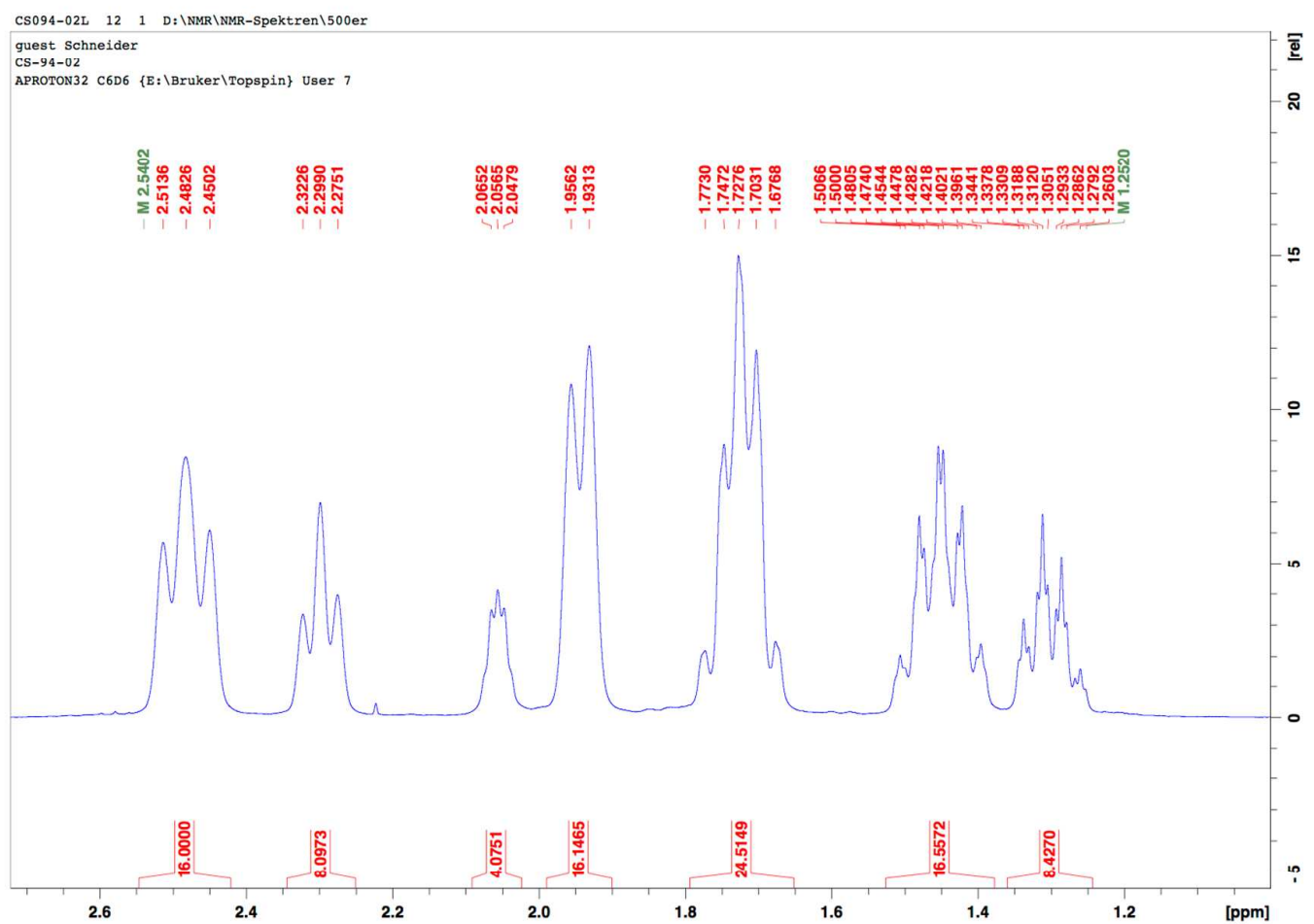


${ }^{13} C\left\{{ }^{1} H\right\}$ NMR spectrum

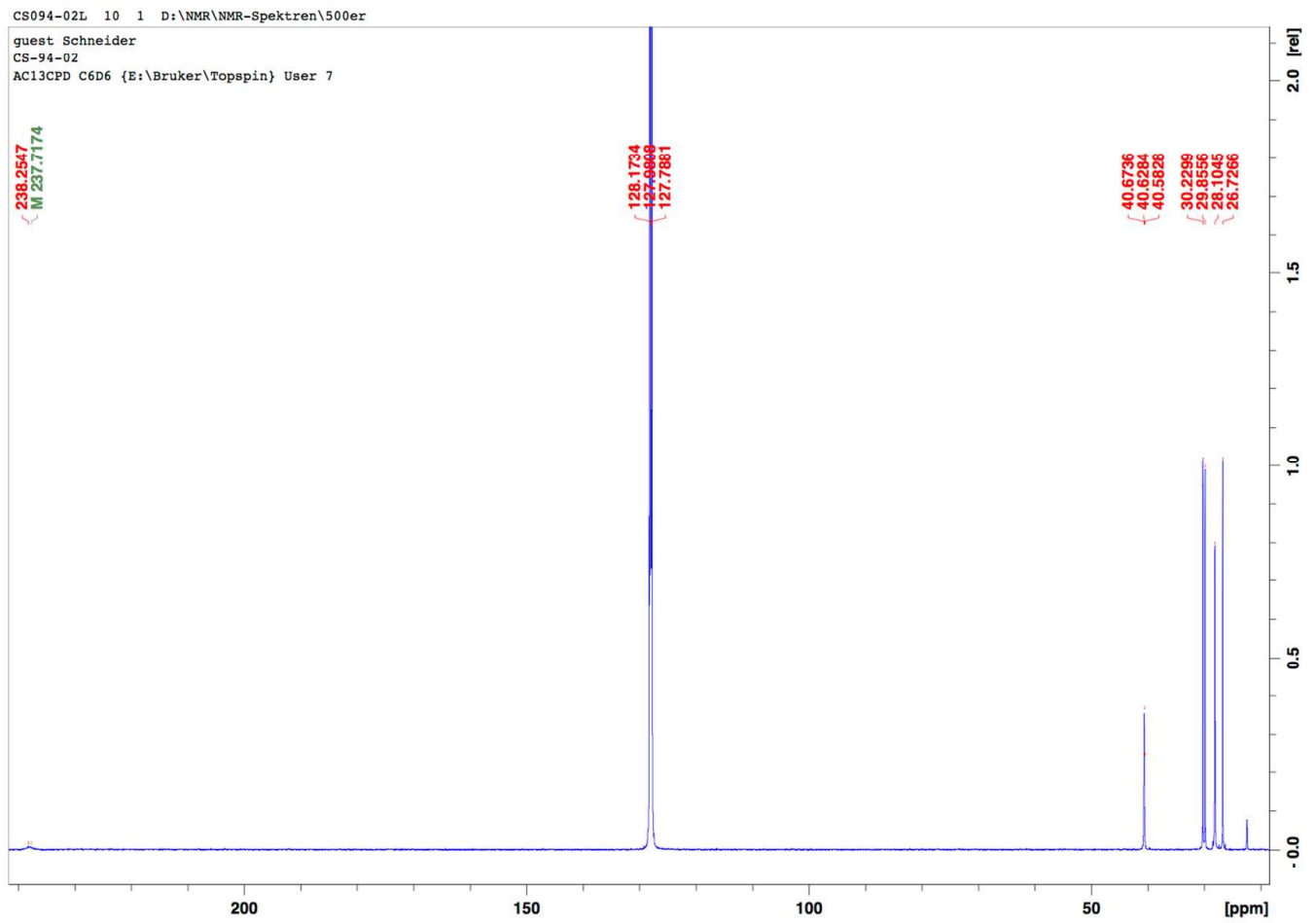

The signal at 128.68 represents the $\mathrm{C}_{6} \mathrm{D}_{6}$ signal. 
${ }^{31} P\left\{{ }^{l} H\right\}$ NMR spectrum

CS094-02L $13 \quad 1 \quad$ D: \NMR \NMR-Spektren $5500 e r$

\begin{tabular}{|l} 
guest Schneider \\
CS $-94-02$
\end{tabular}

AP31CPD C6D6 \{E: \Bruker \Topspin\} User 7

$\underline{\underline{\underline{\sigma}}}$
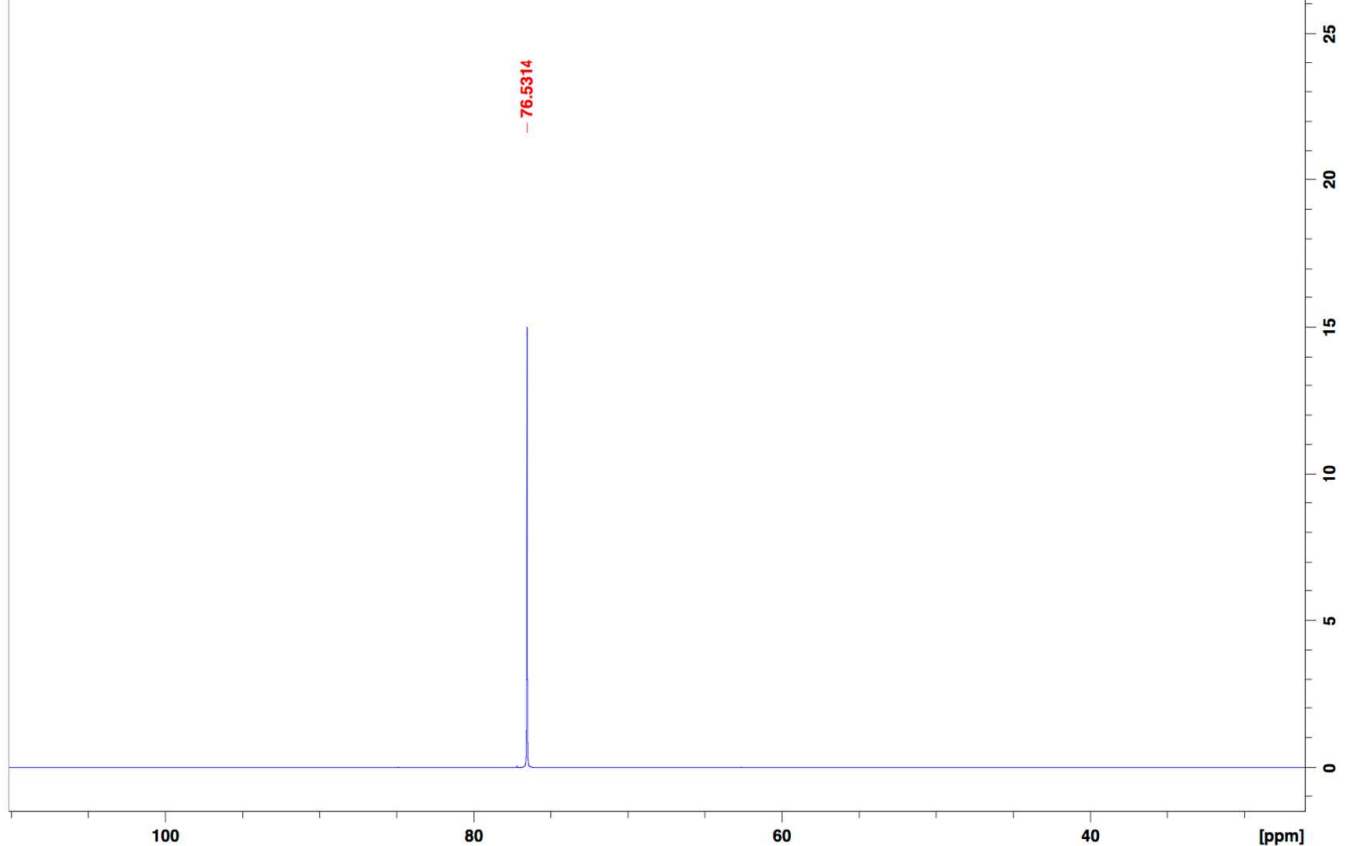


\section{Complex 6b}

${ }^{1} H$ NMR spectrum

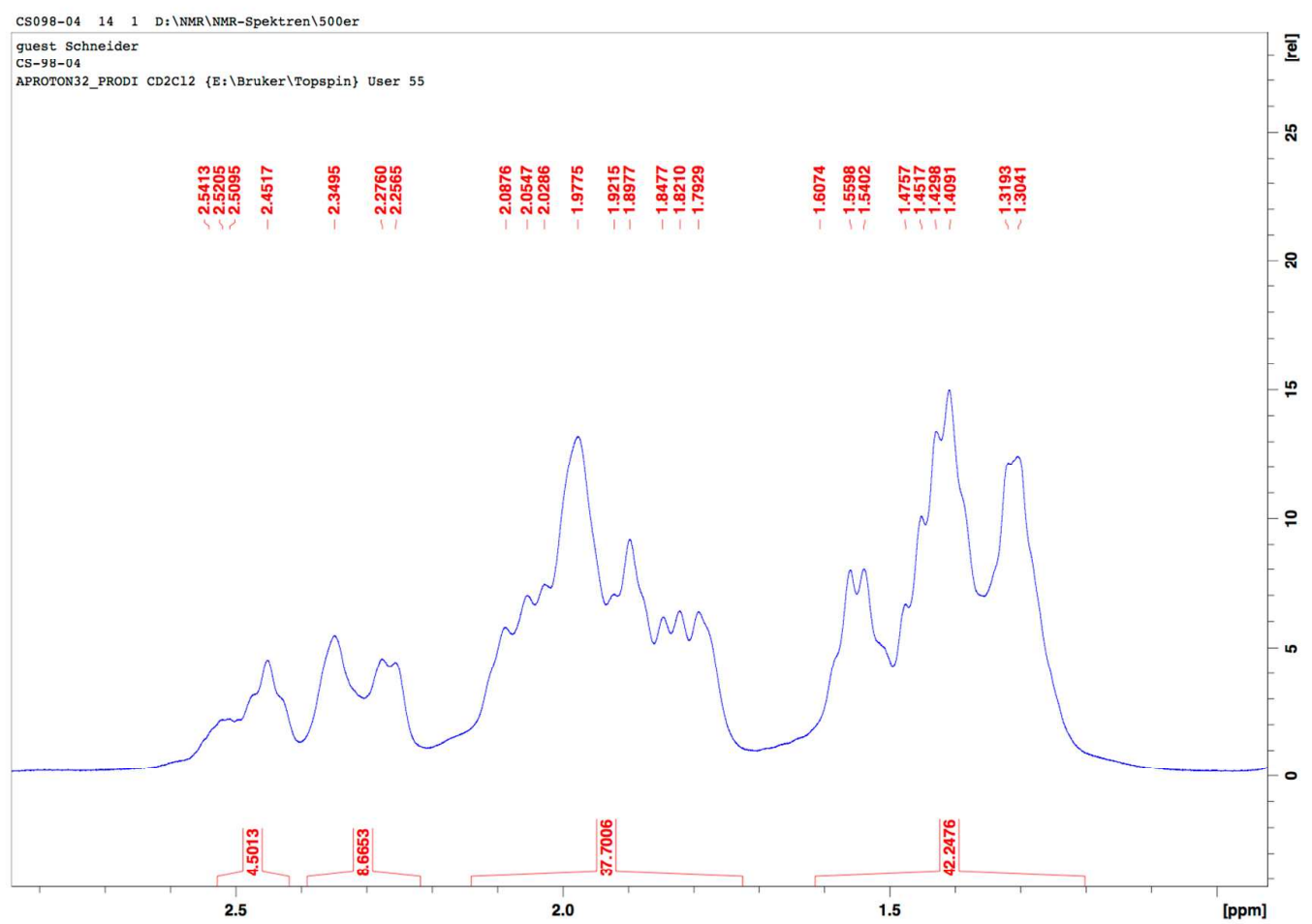


${ }^{13} C\left\{{ }^{1} H\right\}$ NMR spectrum

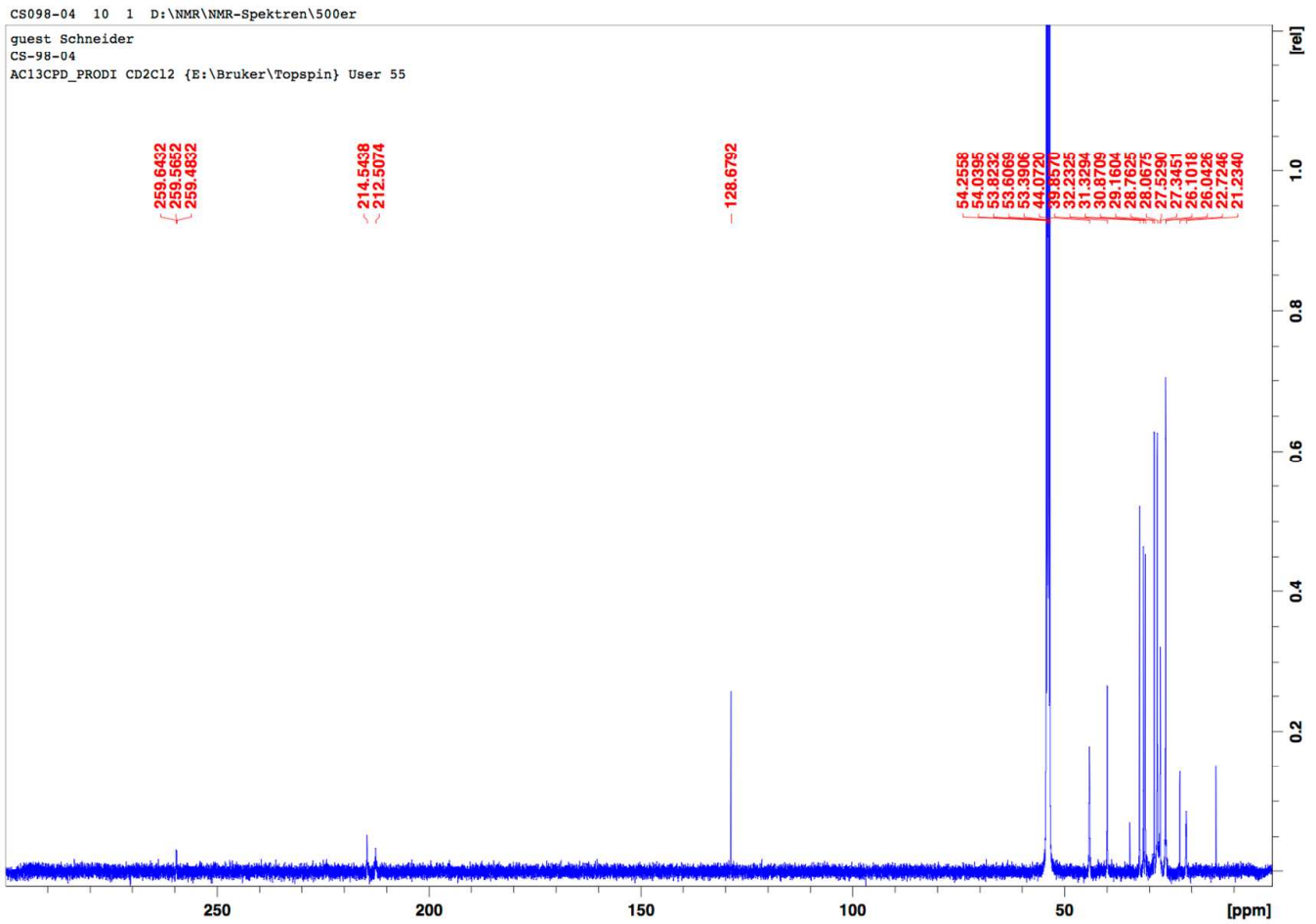

The signal at 53.84 represents the $\mathrm{CD}_{2} \mathrm{Cl}_{2}$ signal and the signal at 128.68 can be assigned to benzene from the preparation.

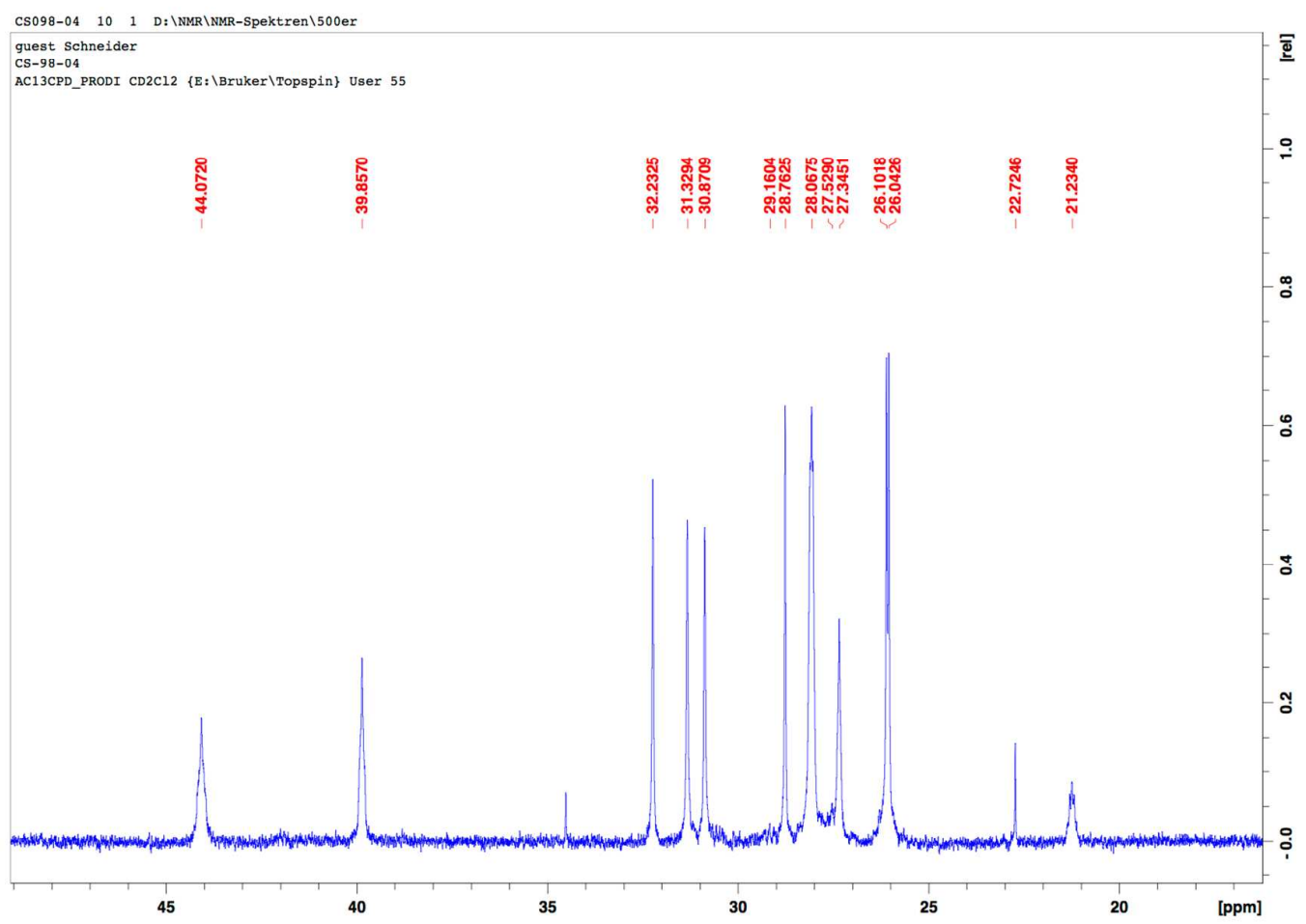


${ }^{31} P\left\{{ }^{1} H\right\} N M R$ spectrum

CS-098-04 $12 \quad 1 \quad$ D: \MMR \NMR-Spektren\500er

guest Schneider
CS-98-04
AP31CPD CD2C12 \{B: :Bruker \Topspin\} User 55
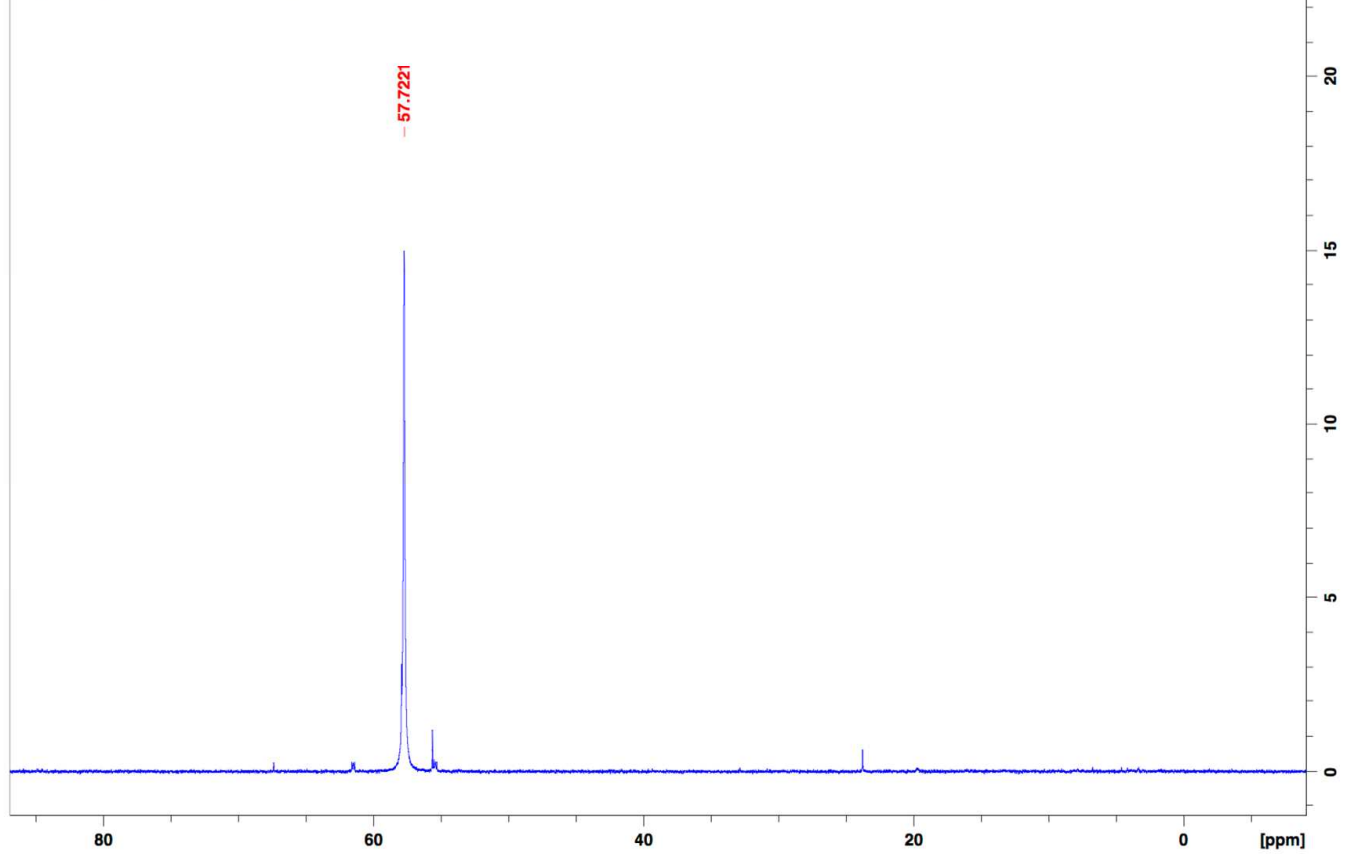


\section{Crystallographic details}

The crystal data of 3a were collected on a BRUKER D8 QUEST diffractometer with a CMOS area detector and multi-layer mirror monochromated $\mathrm{Mo}_{\mathrm{K} \alpha}$ radiation. The structure was solved using intrinsic phasing method (SHELXT), refined with the SHELXLprogram ${ }^{1}$ and expanded using Fourier techniques. All non-hydrogen atoms were refined anisotropically. Hydrogen atoms were included in structure factor calculations. All hydrogen atoms were assigned to idealised geometric positions. Crystal data for 3a: $\mathrm{C}_{33} \mathrm{H}_{39} \mathrm{FeN}_{2} \mathrm{O}_{3} \mathrm{P}, M_{\mathrm{r}}=598.48$, colourless plate, $0.177 \times 0.096 \times 0.047 \mathrm{~mm}^{3}$, triclinic space group $P-1, \quad a=9.396(2) \AA, \quad b=9.9612(16) \AA, \quad c=16.940(2) \AA, \quad \alpha=85.736(12)^{\circ}$, $\beta=85.929(17)^{\circ}, \quad \gamma=78.230(19)^{\circ}, \quad V=1545.4(5) \AA^{3}, Z=2, \quad \rho_{\text {calcd }}=1.286 \mathrm{~g} \cdot \mathrm{cm}^{-3}, \quad \mu=0.575 \mathrm{~mm}^{-1}$, $F(000)=632, T=100(2) \mathrm{K}, R_{1}=0.0649, w R^{2}=0.0848,6504$ independent reflections $\left[2 \theta \leq 53.604^{\circ}\right]$ and 370 parameters.

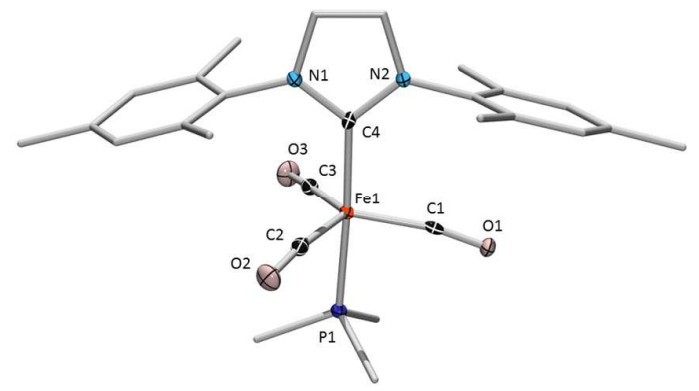

Figure S1. Molecular structure of $\mathbf{3 a}$ in the solid state. Thermal ellipsoids are shown at the 50\% probability level. Hydrogen atoms and some ellipsoids of the ligands are omitted for clarity. Selected bond length $[\AA]$ and angles $\left[^{\circ}\right]$ : Fe1-C4 1.984(2), Fe1-P1 2.198(1); C4-Fe1-P1 176.77(6).

The crystal data of 4a were collected on a Bruker D8-QUEST diffractometer with a CCD area detector and multi-layer mirror monochromated $\mathrm{Mo}_{\mathrm{K} \alpha}$ radiation. The structure was solved using direct methods, refined with the Shelx software package ${ }^{1}$ and expanded using Fourier techniques. All non-hydrogen atoms were refined anisotropically. Hydrogen atoms were included in structure factor calculations. All hydrogen atoms were assigned to idealised geometric positions. The Uii displacement parameters of atoms C40, C42, C41A and C44A were restrained with ISOR keyword to approximate isotropic behavior. Crystal data for $4 \mathrm{a}: \mathrm{C}_{39} \mathrm{H}_{66} \mathrm{FeO}_{3} \mathrm{P}_{2}, M_{\mathrm{r}}=700.71$, colourless block, $0.133 \times 0.12 \times 0.113 \mathrm{~mm}^{3}$, monoclinic space group $P 2{ }_{1} / n, a=15.509(6) \AA, b=12.270(4) \AA, c=19.698(5) \AA, \beta=95.84(3)^{\circ}$, $V=3729(2) \AA^{3}, \quad Z=4, \quad \rho_{\text {calcd }}=1.248 \mathrm{~g} \cdot \mathrm{cm}^{-3}, \quad \mu=0.525 \mathrm{~mm}^{-1}, \quad F(000)=1520, \quad T=100(2) \mathrm{K}$, $R_{l}=0.0774, w R^{2}=0.1089,7943$ independent reflections $\left[2 \theta \leq 53.7^{\circ}\right]$ and 460 parameters. 


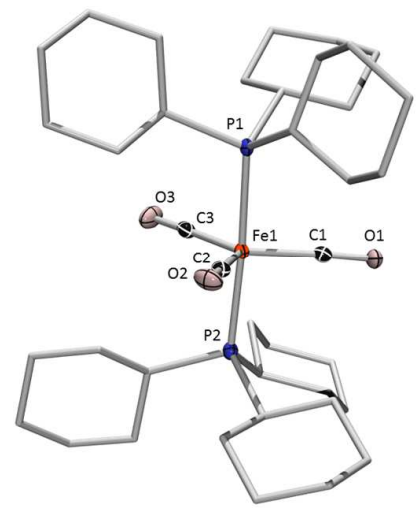

Figure S2. Molecular structure of $\mathbf{4 a}$ in the solid state. Thermal ellipsoids are shown at the $50 \%$ probability level. Hydrogen atoms and some ellipsoids of the ligands are omitted for clarity. Selected bond length $[\AA]$ and angles [ํ]: Fe1-P1 2.2416(10), Fe1-P2 2.2422(10); P1-Fe1-P2 176.07(2).

The crystal data of 6a were collected on a Bruker D8-QUEST diffractometer with a CCD area detector and multi-layer mirror monochromated $\mathrm{Mo}_{\mathrm{K} \alpha}$ radiation. The structure was solved using direct methods, refined with the Shelx software package ${ }^{1}$ and expanded using Fourier techniques. All non-hydrogen atoms were refined anisotropically. Hydrogen atoms were included in structure factor calculations. All hydrogen atoms were assigned to idealised geometric positions. Crystal data for $6 \mathbf{a}: \mathrm{C}_{55} \mathrm{H}_{92} \mathrm{Fe}_{2} \mathrm{O}_{5} \mathrm{P}_{4}$, $M_{\mathrm{r}}=1068.87$, red block, $0.213 \times 0.174 \times 0.101 \mathrm{~mm}^{3}$, triclinic space group $P-1, a=10.900(4) \AA$, $b=12.120(4) \AA, \quad c=21.564(7) \AA, \quad \alpha=82.724(14)^{\circ}, \quad \beta=76.397(12)^{\circ}, \quad \gamma=85.928(16)^{\circ}$, $V=2744.0(16) \AA^{3}, \quad Z=2, \quad \rho_{\text {calcd }}=1.294 \mathrm{~g} \cdot \mathrm{cm}^{-3}, \quad \mu=0.690 \mathrm{~mm}^{-1}, \quad F(000)=1148, \quad T=100(2) \mathrm{K}$, $R_{l}=0.0553, w R^{2}=0.0896,11593$ independent reflections $\left[2 \theta \leq 53.52^{\circ}\right]$ and 595 parameters.

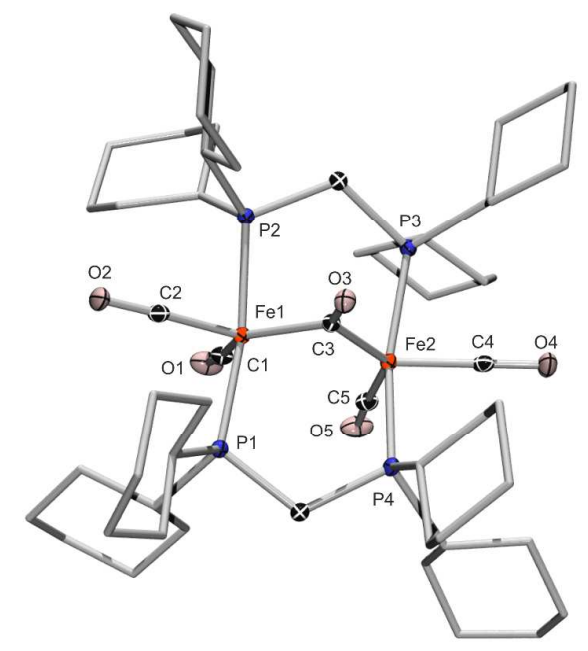

Figure S3. Molecular structure of $6 \mathbf{a}$ in the solid state. Thermal ellipsoids are shown at the $50 \%$ probability level. Hydrogen atoms and some ellipsoids of the ligands are omitted for clarity. Selected bond length $[\AA]$ and angles $\left[{ }^{\circ}\right]$ : Fe1-Fe2 2.7613(10), Fe1-P1 2.2557(9), Fe1-P2 2.2349(10), Fe2-P3 2.2550(9), Fe2-P4 2.2558(10), Fe1-C3 1.967(1), Fe2-C3 2.003(2); P1-Fe1-P2 163.16(3), P3-Fe2-P4 $167.22(2)$. 
The crystal data of $\mathbf{1 b}$ were collected on a BRUKER D8 QUEST diffractometer with a CMOS area detector and multi-layer mirror monochromated $\mathrm{Mo}_{\mathrm{K} \alpha}$ radiation. The structure was solved using the intrinsic phasing method (SHELXT), refined with the SHELXL program ${ }^{1}$ and expanded using Fourier techniques. All non-hydrogen atoms were refined anisotropically. Hydrogen atoms were included in structure factor calculations. All hydrogen atoms were assigned to idealised geometric positions. Crystal data for 1 b: $\mathrm{C}_{22} \mathrm{H}_{33} \mathrm{Cl}_{3} \mathrm{FeGaO}_{4} \mathrm{P}, M_{\mathrm{r}}=624.37$, colourless block, $0.304 \times 0.094 \times 0.078 \mathrm{~mm}^{3}$, orthorhombic space group P212121, $a=11.2213(4) \AA, \quad b=14.6564(6) \AA, \quad c=16.1887(6) \AA$, $V=2662.46(17) \AA^{3}, \quad Z=4, \quad \rho_{\text {calcd }}=1.558 \mathrm{~g} \cdot \mathrm{cm}^{-3}, \quad \mu=1.944 \mathrm{~mm}^{-1}, \quad F(000)=1280, \quad T=100(2) \mathrm{K}$, $R_{l}=0.0258, w R^{2}=0.0544,5660$ independent reflections $\left[2 \theta \leq 53.788^{\circ}\right]$ and 289 parameters.

The crystal data of $\mathbf{2 b}$ were collected on a Bruker D8-QUEST diffractometer with a CCD area detector and multi-layer mirror monochromated $\mathrm{Mo}_{\mathrm{K} \alpha}$ radiation. The structure was solved using direct methods, refined with the Shelx software package ${ }^{1}$ and expanded using Fourier techniques. All non-hydrogen atoms were refined anisotropically. Hydrogen atoms were included in structure factors calculations. All hydrogen atoms were assigned to idealised geometric positions. Crystal data for $\mathbf{2 b}$ : $\mathrm{C}_{26} \mathrm{H}_{26} \mathrm{Cl}_{5} \mathrm{FeGaN}_{2} \mathrm{O}_{4}, M_{\mathrm{r}}=733.31$, colourless block, $0.211 \times 0.093 \times 0.079 \mathrm{~mm}^{3}$, Monoclinic space group $P 2_{1} / n, a=10.7556(18) \AA, b=21.110(3) \AA, c=14.383(4) \AA, \beta=107.649(12)^{\circ}, V=3112.1(10) \AA^{3}$,

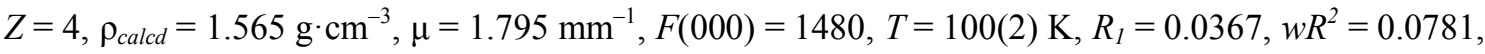
6541 independent reflections $\left[2 \theta \leq 53.62^{\circ}\right]$ and 358 parameters.

The crystal data of $\mathbf{3 b}$ were collected on a Bruker D8-QUEST diffractometer with a CCD area detector and multi-layer mirror monochromated $\mathrm{Mo}_{\mathrm{K} \alpha}$ radiation. The structure was solved using direct methods, refined with the Shelx software package ${ }^{1}$ and expanded using Fourier techniques. All non-hydrogen atoms were refined anisotropically. Hydrogen atoms were included in structure factor calculations. All hydrogen atoms were assigned to idealised geometric positions. The unit cell contains one solvent molecule which have been treated as a diffuse contribution to the overall scattering without specific atom positions by SQUEEZE/PLATON. Crystal data for 3b: $\mathrm{C}_{27} \mathrm{H}_{33} \mathrm{Cl}_{3} \mathrm{FeGaN}_{2} \mathrm{O}_{3} \mathrm{P}, M_{\mathrm{r}}=696.44$, colourless plate, $0.192 \times 0.101 \times 0.048 \mathrm{~mm}^{3}, \quad$ monoclinic space group $P 2_{1} / n, \quad a=11.196(3) \AA$, $b=22.850(4) \AA, c=13.571(2) \AA, \beta=102.173(10)^{\circ}, V=3393.9(12) \AA^{3}, Z=4, \rho_{\text {calcd }}=1.363 \mathrm{~g} \cdot \mathrm{cm}^{-3}$, $\mu=1.532 \mathrm{~mm}^{-1}, \quad F(000)=1424, \quad T=100(2) \mathrm{K}, \quad R_{l}=0.0383, \quad w R^{2}=0.0741, \quad 7185 \quad$ independent reflections $\left[2 \theta \leq 53.62^{\circ}\right]$ and 352 parameters.

The crystal data of 3c were collected on a BRUKER D8 QUEST diffractometer with a CMOS area detector and multi-layer mirror monochromated $\mathrm{Mo}_{\mathrm{K} \alpha}$ radiation. The structure was solved using intrinsic phasing method (SHELXT), refined with the SHELXLprogram ${ }^{1}$ and expanded using Fourier techniques. All non-hydrogen atoms were refined anisotropically. Hydrogen atoms were included in 
structure factor calculations. All hydrogen atoms were assigned to idealised geometric positions. Crystal data for 3c: $\mathrm{C}_{39} \mathrm{H}_{45} \mathrm{Cl}_{3} \mathrm{FeGaN}_{2} \mathrm{O}_{3} \mathrm{P}, M_{\mathrm{r}}=852.66$, colourless block, $0.162 \times 0.081 \times 0.049 \mathrm{~mm}^{3}$, monoclinic space group $P 21 / c, a=9.826(2) \AA, b=17.838(8) \AA, c=22.715(8) \AA, \beta=101.19(2)^{\circ}$, $V=3906(3) \AA^{3}, \quad Z=4, \quad \rho_{\text {calcd }}=1.450 \mathrm{~g} \cdot \mathrm{cm}^{-3}, \quad \mu=1.346 \mathrm{~mm}^{-1}, \quad F(000)=1760, \quad T=100(2) \mathrm{K}$, $R_{l}=0.0724, w R^{2}=0.1416,8380$ independent reflections $\left[2 \theta \leq 53.712^{\circ}\right]$ and 460 parameters.

The crystal data of $\mathbf{4 b}$ were collected on a Bruker D8-QUEST diffractometer with a CCD area detector and multi-layer mirror monochromated $\mathrm{Mo}_{\mathrm{K} \alpha}$ radiation. The structure was solved using direct methods, refined with the Shelx software package ${ }^{1}$ and expanded using Fourier techniques. All non-hydrogen atoms were refined anisotropically. Hydrogen atoms were included in structure factor calculations. All hydrogen atoms were assigned to idealised geometric positions. Crystal data for $\mathbf{4 b}$ : $\mathrm{C}_{53} \mathrm{H}_{81} \mathrm{Cl}_{6} \mathrm{FeGa}_{2} \mathrm{O}_{3} \mathrm{P}_{2}, M_{\mathrm{r}}=1236.10$, colourless block, $0.168 \times 0.165 \times 0.122 \mathrm{~mm}^{3}$, triclinic space group $P-1, \quad a=11.684(2) \AA, \quad b=15.787(3) \AA, \quad c=16.292(3) \AA, \quad \alpha=101.106(8)^{\circ}, \quad \beta=95.429(8)^{\circ}$, $\gamma=96.512(9)^{\circ}, \quad V=2908.6(10) \AA^{3}, \quad Z=2, \quad \rho_{\text {calcd }}=1.411 \mathrm{~g} \cdot \mathrm{cm}^{-3}, \quad \mu=1.536 \mathrm{~mm}^{-1}, \quad F(000)=1286$, $T=100(2) \mathrm{K}, R_{l}=0.0442, w R^{2}=0.0784,12053$ independent reflections $\left[2 \theta \leq 53.518^{\circ}\right]$ and 605 parameters.

The crystal data of $\mathbf{5 b}$ were collected on a BRUKER D8 QUEST diffractometer with a CMOS area detector and multi-layer mirror monochromated $\mathrm{Mo}_{\mathrm{K} \alpha}$ radiation. The structure was solved using intrinsic phasing method (SHELXT), refined with the SHELXLprogram ${ }^{1}$ and expanded using Fourier techniques. All non-hydrogen atoms were refined anisotropically. Hydrogen atoms were included in structure factor calculations. All hydrogen atoms were assigned to idealised geometric positions. The displacement parameters of atoms $\mathrm{Ga} 3$ and $\mathrm{Ga} 6$ were constrained to the same value. The displacement parameters of atoms C51, O51, C110, O110, Ga2, Ga3, Ga5, Ga6, Cl13, Cl4, Cl6, Cl5, Cl17, Cl18, Cl120, Cl121, Cl122, Cl123, Cl125 and Cl126 were restrained to the same value with similarity restraint SIMU. The Uii displacement parameters of atom C72 were restrained with the ISOR keyword to approximate isotropic behavior. Crystal data for 5b: $\mathrm{C}_{96} \mathrm{H}_{101} \mathrm{Cl}_{12} \mathrm{FFe}_{2} \mathrm{Ga}_{4} \mathrm{~N}_{8} \mathrm{O}_{6}, M_{\mathrm{r}}=2297.82$, colourless block, $\quad 0.219 \times 0.176 \times 0.094 \mathrm{~mm}^{3}$, monoclinic space group $P 21 / n, a=21.114(4) \AA$, $b=20.940(4) \AA, \quad c=23.476(4) \AA, \quad \beta=94.039(7)^{\circ}, \quad V=10353(3) \AA^{3}, \quad Z=4, \quad \rho_{\text {calcd }}=1.474 \mathrm{~g} \cdot \mathrm{cm}^{-3}$, $\mu=1.665 \mathrm{~mm}^{-1}, \quad F(000)=4680, \quad T=100(2) \mathrm{K}, \quad R_{l}=0.0873, \quad w R^{2}=0.1547,21990 \quad$ independent reflections $\left[2 \theta \leq 53.496^{\circ}\right]$ and 1292 parameters.

The crystal data of $\mathbf{6 b}$ were collected on a Bruker D8-QUEST diffractometer with a CCD area detector and multi-layer mirror monochromated $\mathrm{Mo}_{\mathrm{K} \alpha}$ radiation. The structure was solved using direct methods, refined with the Shelx software package ${ }^{1}$ and expanded using Fourier techniques. All non-hydrogen atoms were refined anisotropically. Hydrogen atoms were included in structure factor calculations. All hydrogen atoms were assigned to idealised geometric positions. The unit cell contains one solvent 
molecule which has been treated as a diffuse contribution to the overall scattering without specific atom positions by SQUEEZE/PLATON. The displacement parameters of atoms C132 and C182 were constrained to the same value. Crystal data for $6 \mathbf{b}: \mathrm{C}_{140} \mathrm{H}_{209} \mathrm{Cl}_{12} \mathrm{~F}_{5} \mathrm{Fe}_{4} \mathrm{Ga}_{4} \mathrm{O}_{10} \mathrm{P}_{8}, M_{\mathrm{r}}=3322.51$, red plate, $0.206 \times 0.075 \times 0.046 \mathrm{~mm}^{3}$, triclinic space group $P-1, a=16.566(3) \AA, b=18.049(3) \AA$, $c=28.340(5) \AA, \quad \alpha=93.576(7)^{\circ}, \quad \beta=102.578(7)^{\circ}, \quad \gamma=100.080(7)^{\circ}, \quad V=8098(2) \AA^{3}, \quad Z=2$, $\rho_{\text {calcd }}=1.363 \mathrm{~g} \cdot \mathrm{cm}^{-3}, \mu=1.336 \mathrm{~mm}^{-1}, F(000)=3452, T=100(2) \mathrm{K}, R_{l}=0.0528, w R^{2}=0.0971,34165$ independent reflections $\left[2 \theta \leq 53.42^{\circ}\right]$ and 1757 parameters.

Crystallographic data for 1b (CCDC-1448424), 2b (CCDC-1448423), 3a (CCDC-1448426), 3b (CCDC-1448420), 3c (CCDC-1448421), 4a (CCDC-1448418), 4b (CCDC-1448422), 5b (CCDC1448425), 6a (CCDC-1448417) and $\mathbf{6 b}$ (CCDC-1448419) have been deposited with the Cambridge Crystallographic Data Center. These data can be obtained free of charge from The Cambridge Crystallographic Data Centre via www.ccdc.cam.ac.uk/data_request/cif 


\section{References}

(1) Sheldrick, G. Acta Cryst. 2008, A64, 112. 